\title{
Impact of Hydraulic Fractures on Type Curves for Horizontal Wells in CBM Reservoirs
}

\author{
David Christopher Bell \\ West Virginia University
}

Follow this and additional works at: https://researchrepository.wvu.edu/etd

\section{Recommended Citation}

Bell, David Christopher, "Impact of Hydraulic Fractures on Type Curves for Horizontal Wells in CBM Reservoirs" (2011). Graduate Theses, Dissertations, and Problem Reports. 2241.

https://researchrepository.wvu.edu/etd/2241

This Thesis is protected by copyright and/or related rights. It has been brought to you by the The Research Repository @ WVU with permission from the rights-holder(s). You are free to use this Thesis in any way that is permitted by the copyright and related rights legislation that applies to your use. For other uses you must obtain permission from the rights-holder(s) directly, unless additional rights are indicated by a Creative Commons license in the record and/ or on the work itself. This Thesis has been accepted for inclusion in WVU Graduate Theses, Dissertations, and Problem Reports collection by an authorized administrator of The Research Repository @ WVU. For more information, please contact researchrepository@mail.wvu.edu. 
Impact of Hydraulic Fractures on Type Curves for Horizontal Wells in CBM Reservoirs

David Christopher Bell

\author{
Thesis submitted to the \\ College of Engineering and Mineral Resources \\ at West Virginia University \\ In partial fulfillment of the requirements \\ for the degree of
}

Master of Science

In

Petroleum and Natural Gas Engineering

\author{
Kashy Aminian, Ph.D. Chair \\ Samuel Ameri, M.S. \\ Gary Winn, Ph.D.
}

Department of Petroleum and Natural Gas Engineering

Morgantown, West Virginia

2011

Keywords: Unconventional Reservoirs, Coalbed Methane, CBM, Horizontal Wells, Type Curves, Gas Production Prediction.

Copyright 2011 David Christopher Bell 


\section{ABSTRACT \\ Predicting the Performance of Horizontal Wells in CBM Reservoirs with Hydraulic Fractures}

\section{David Christopher Bell}

As production technologies continue to increase, more and more unconventional natural gas plays are becoming economical and attractive to produce. CBM, or coalbed methane, currently accounts for approximately ten percent ${ }^{27}$ of all natural gas production in the U.S., and that number is increasing. Therefore, it is critical to understand what makes a reservoir a viable option for production development.

Many current tools used to predict the performance of a reservoir rely heavily on unknowns about the formation, and are therefore risky and complex. Numerical methods and computer simulations can greatly aid in the evaluation, but still remain an incomplete description of the entire picture. Type curves need less information about the reservoir in question and often provide a great level of accuracy in predicting the performance of the reservoir over the span of its production. Type curves exist for many different types of reservoirs, but more investigation is required for creating type curves of hydraulically fractured, horizontal coalbed methane reservoirs.

This research has helped to demonstrate that type curves for this category of reservoirs can be useful and in time, fully understood. Fracturing characteristics had more impact on the production of these reservoirs than reservoir characteristics themselves. Fracture conductivity and fracture half-length have moderate impact on type curves, as well as reservoir desorption time and coal gas concentration. An equation for dimensionless peak flow rate was also investigated. 


\section{ACKNOWLEDGEMENTS}

I'd like to thank all those who've helped me to reach this point in my academic career. All of those who have supported me and allowed me to excel to this point, I appreciate your patience and guidance.

I'd also like to thank the Mechanical Engineering department for providing me with a strong engineering background. Furthermore, I'd like to thank this department for their professionalism. First, Beverly, thank you for helping to keep all of us straight. You're an integral part of our success. Chair and Professor Sam Ameri's support through all of this has also been required for my success. Dr. Ilkin Bilgesu has also provided me with an excellent structure of guidance, wisdom, and knowledge. Dr. Gary Winn helped to pave the path for my success and spark for constant desire to further learn in all engineering fields. And finally, my advisor, Dr. Kashy Aminian has provided me the insight l've needed to complete this project. His understanding and knowledge of the subjects covered are of the highest level, and rival that of any other expert.

Thank you for the guidance, support, knowledge, and care from all those involved. 


\section{TABLE OF CONTENTS}

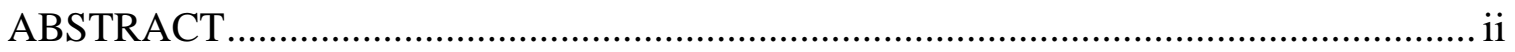

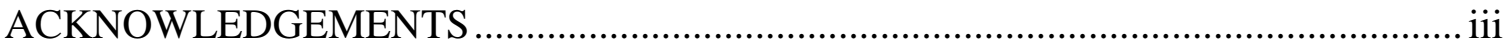

TABLE OF CONTENTS ......................................................................................... iv

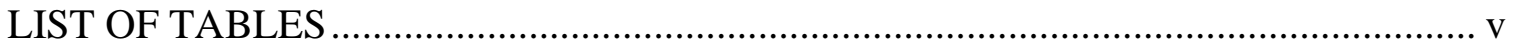

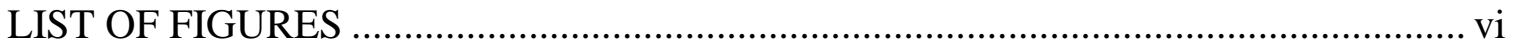

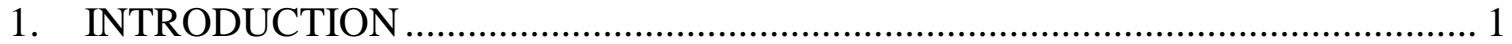

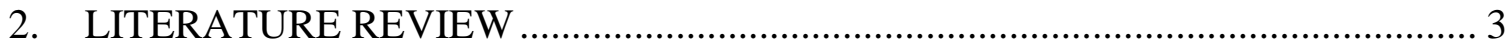

2.1 Coalbed Methane Reservoirs ............................................................................... 3

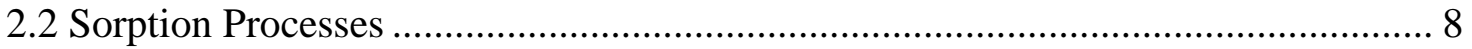

2.3 Porosity and Permeability ………………………....................................... 9

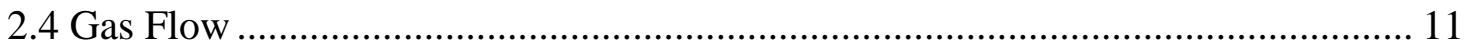

2.5 Horizontal Wells

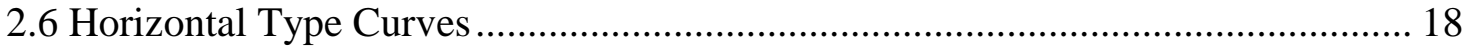

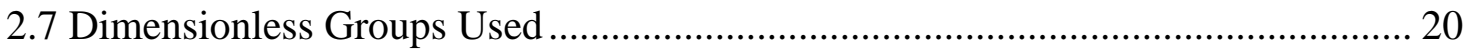

2.8 Type Curves for Coalbed Methane ……………............................................... 22

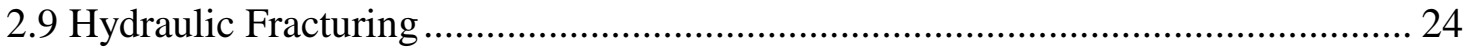

2.10 Numerical Models and Assumptions ................................................................. 26

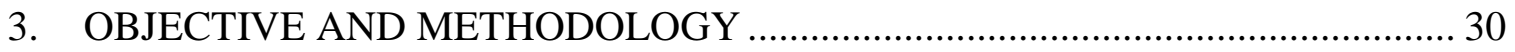

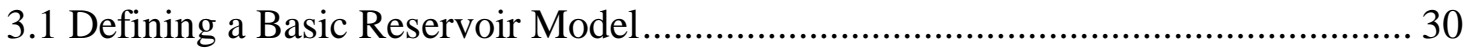

3.2 Model Characteristics and Variables to be Changed .............................................. 32

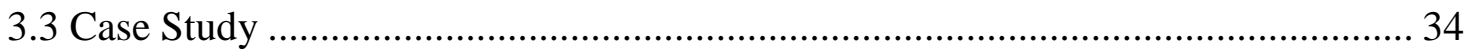

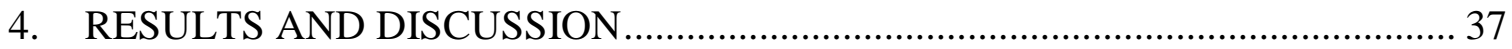

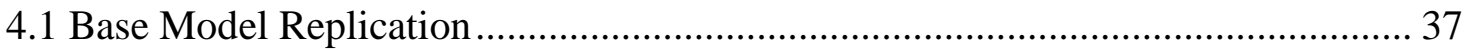

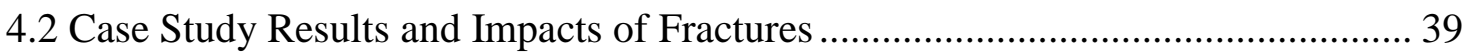

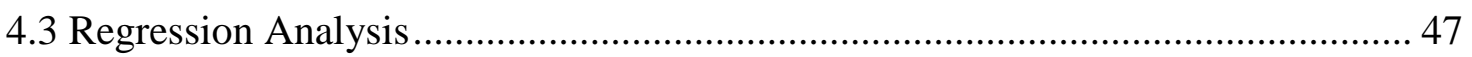

5. CONCLUSIONS AND RECOMMENDATIONS ……………………................ 49

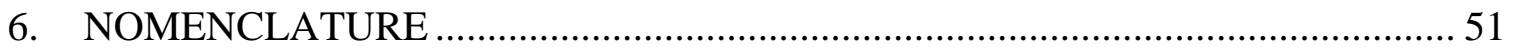

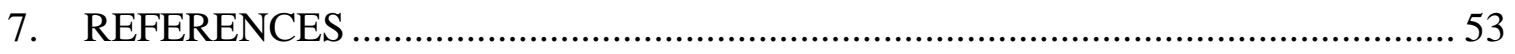




\section{LIST OF TABLES}

Table 1. ASTM Coal Rank ${ }^{9}$..................................................................................... 6

Table 2. Shape Related Skin Factors for Horizontal Wells ........................................ 17

Table 3. Values and Ranges of Basic Reservoir Inputs ............................................. 34

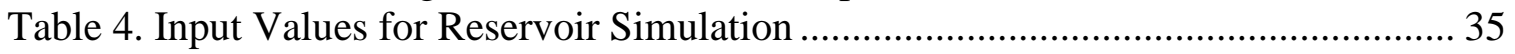

Table 5. Fracture Values For Reservoir Simulation ................................................... 36 


\section{LIST OF FIGURES}

Figure 1. Effects of Horizontal Well Penetration on Type Curves ${ }^{11}$................................. 3

Figure 2. Effects of Drainage Area Shape on Type Curves ${ }^{11}$.......................................... 4

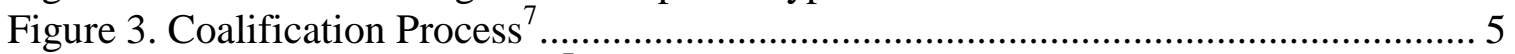

Figure 4. Gas Generation in $\mathrm{Coal}^{7}$..................................................................... 7

Figure 5. Production Decline for Vertical Wells ${ }^{10}$....................................................... 13

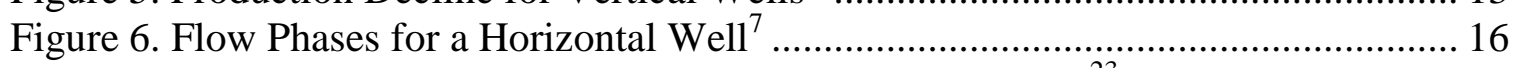

Figure 7. Early-time Production Type Curve for Horizontal Well ${ }^{23}$ ……......................... 19

Figure 8. Late-time Production Type Curve for Horizontal Well ${ }^{23}$.................................. 19

Figure 9. Impact of Drainage Area on the Type Curve when Comparing $\mathrm{L} / \mathrm{Xe}=0.25$ for

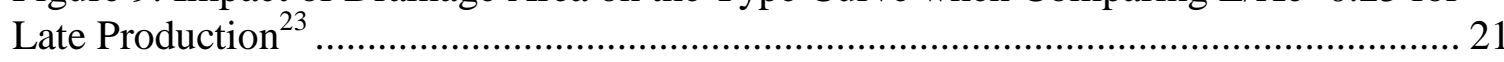

Figure 10. Impact of Drainage Area on the Type Curve when Comparing $\mathrm{L} / \mathrm{Xe}=0.50$ for

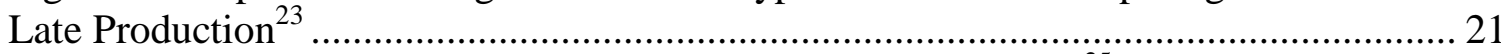

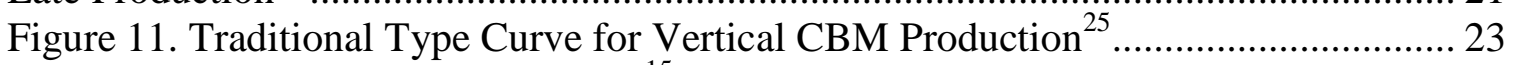

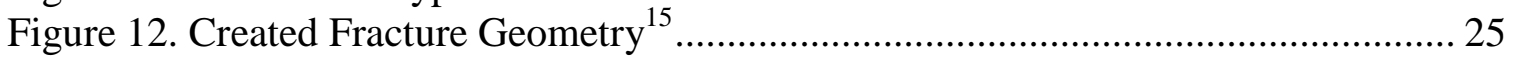

Figure 13. Original Model Shape............................................................................... 31

Figure 14. Three-Dimensional 80 Acre Model............................................................. 32

Figure 15. Horizontal Well Placement and Length Ratios .............................................. 33

Figure 16. Early Production Impacted by L/Xe Ratio ....................................................... 37

Figure 17. Late Production Impacted by L/Xe Ratio ....................................................... 38

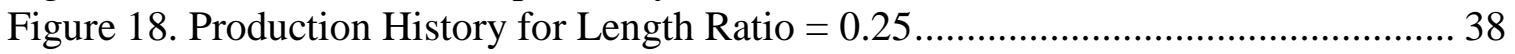

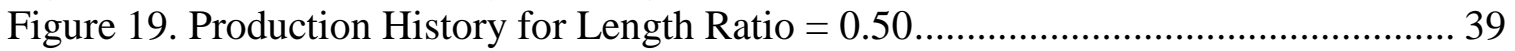

Figure 20. Effects of Fracture Parallel to High Permeability Direction ........................... 40

Figure 21. Effects of Fracture Normal to High Permeability Direction ............................ 41

Figure 22. Effects of Permeability Matrix .................................................................... 41

Figure 23. Effects of Desorption Time ………………............................................... 42

Figure 24. Effects of Desorption Time on Fractured Reservoir ....................................... 43

Figure 25. Effects of Coal Gas Concentration on Fractured Reservoir ............................ 43

Figure 26. Effects of Increased Number of Fractures, $\mathrm{L} / \mathrm{Xe}=0.50$................................ 44

Figure 27. Effects of Increased Number of Fractures, L/Xe $=0.25$................................ 45

Figure 28. Effects of Fracture Half-Length ................................................................ 46

Figure 29. Effects of Fracture Width .............................................................................. 46 


\section{INTRODUCTION}

Unconventional gas production is becoming a more and more important play in the petroleum industry. Its increasing availability makes it an economical alternative to traditional natural gas reservoirs. The three most common types of these newer, unconventional reservoirs are tight sands, coalbed methane (CBM), and gas shales. Traditionally, these plays have been ignored in terms of production, because of the more difficult production techniques needed to provide economical results. However, in recent times, this has begun to change. In 2005 , unconventional gas represented $44 \%$ of U.S. lower-48 onshore production ${ }^{1}$. Because of this great increase in the production and need for unconventional gas plays, tools must exist in order to maximize the analysis and exploitation of these reservoirs.

Coalbed reservoirs are unique on many aspects. Horizontal wells pose particular benefits to the production of these reservoirs because they are able to take advantage of the natural cleat structure of the coalbed. This cleat system consists of the coalbed's naturally occurring matrix of slight variations in the formation of the coal. This matrix is the fundamental process of the adsorption process in the production of the gas from the reservoir. The cleats, essentially, are paths of higher permeability where the gas can travel through.

The cleat matrix, however, is still just a small increase in permeability within a low permeability reservoir. Thus, the prospect of hydraulically fracturing the reservoir may prove to be of great economic benefit. Many considerations must be looked at before this can be confirmed, and that is not the goal of this research. When hydraulic fracturing is implemented, the production of the reservoir will be altered. Knowing how this fracturing process affects the production can be crucial to efficient reservoir engineering. 
The use of type curves has become one of the greatest tools in estimating how a reservoir may act over sufficient time. In order to develop type curves, a significant amount of data is required. This is a key argument for the use of computer-based simulators. Thus, their use in acquiring data and the development of creating such curves is integral, and allows the advancement in the quest for developing these timesaving type curves. 


\section{LITERATURE REVIEW}

\subsection{Coalbed Methane Reservoirs}

The relatively recent decision of industry to produce methane from coalbeds stems from many economical reasons. For one, methane is relatively cheap and is able to be produced from domestic sources. In fact, some U.S. sources estimate approximately 800 trillion cubic feet (Tcf) of methane can be found in American coal beds ${ }^{8}$. This significant abundance, which is considered unconventional in terms of more traditional methane sources, has been formed over millennia in addition to the coal seams in which it is found.

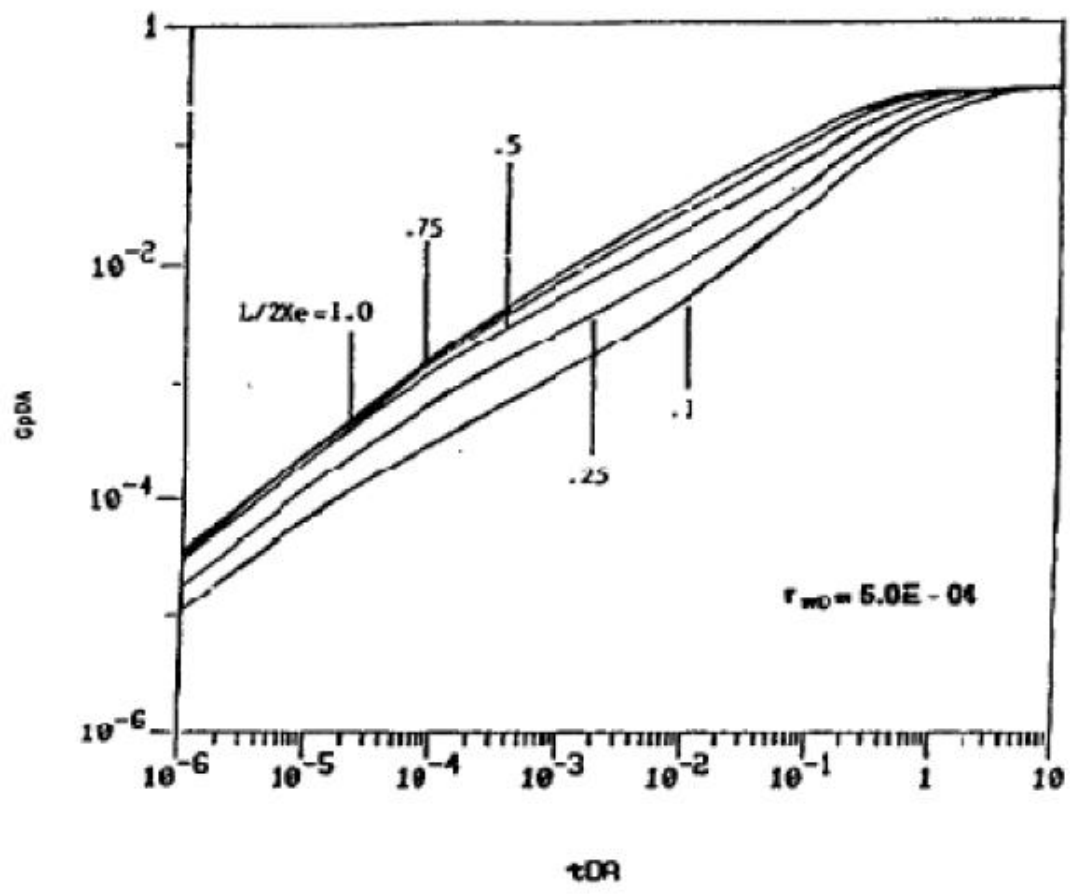

Figure 1. Effects of Horizontal Well Penetration on Type Curves ${ }^{11}$ 


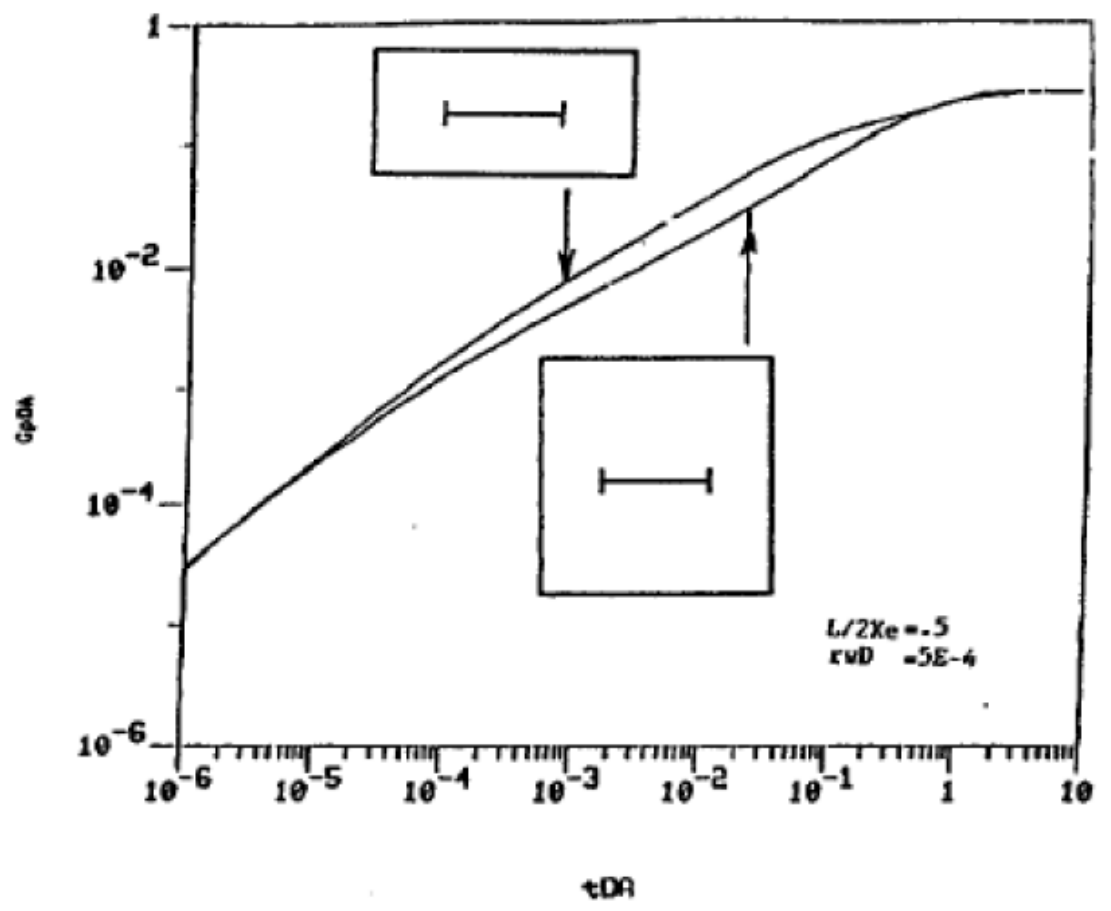

Figure 2. Effects of Drainage Area Shape on Type Curves ${ }^{11}$

At one point, coalbed methane was considered a mining hazard, due to the high risk of explosions which occurred. Now, however, natural gas is viewed with a more positive appearance, and in fact is considered an environmentally friendly fuel. As it is, methane burns more cleanly than any other fossil fuel. However, it is only a direct result of the formation of the coal deposits in which it exists.

Coal begins its formation when plants and other organic material are deposited in swampy areas and are then submerged rapidly enough to limit oxidation but to allow microbial decomposition. Typically, these areas are found near shallow waters of a constant depth. This generally provides a habitat allowing enough organic material, or peat, to accumulate and subsequently can become covered with sediment as geological timeframes pass. 
The peatification process continues until ultimately, the coal is formed into the structure that which it's most familiarly found. The decomposing organics are progressively covered with sediment while physical processes act to compress the peat and biochemical processes alter the make-up of the coal. When the organic mass becomes deeply buried, coalification transforms it through a function of pressure, temperature, and time as shown in Figure 3. Of these parameters, temperature is the most important in the geochemical reactions that occur.

As the coal continues to develop, the effects of temperature and pressure progressively change the molecular structure of the coal. Eventually, a point is reached where methane is evolved in large volumes and is stored in micropores. These micropores can store extraordinary amounts of gas per unit coal, and are released under the desorption process. However, because of the low permeability of the coal, the transport method in which the gas is able to exit the coal is through the natural fracture systems of cleats.

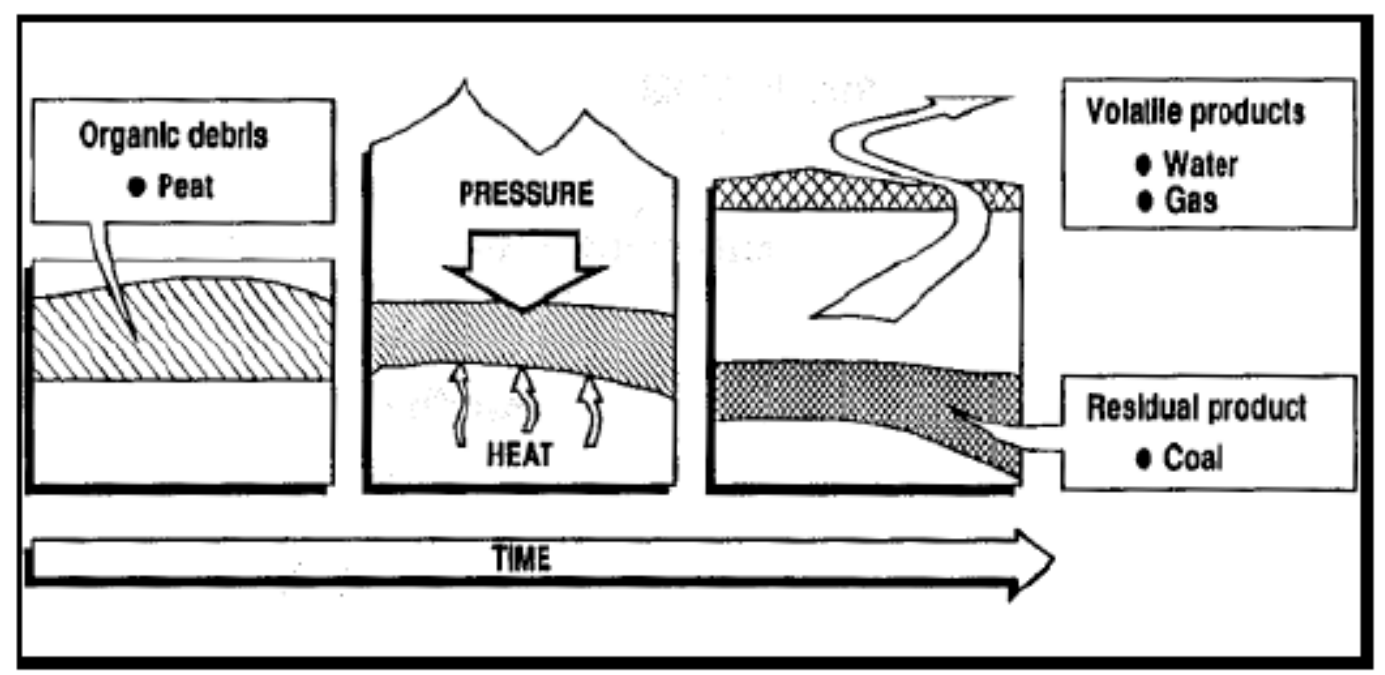

Figure 3. Coalification Process ${ }^{7}$ 
As the coal ages, physical and chemical properties continue to affect the coal. A traditional rank system is used to define the different points of maturity in the coal's lifecycle. Rank is an important aspect of all coal seams, and is also key for the success of any coalbed methane reservoir project because the rank implies specificities about the coal. In particular, the rank can determine the potential gas content, permeability of the rock, and even mechanical and physical properties. Rank will often vary within a seam both laterally and vertically due to its formation processes as discussed previously ${ }^{9}$. Designation of rank as a measure of coal maturity is given in the following table. As the table notes, coals are divided into lignite, sub bituminous, and anthracitic classes before being further subcategorized into groups. There are thirteen groups of coal, and those groups categorize the coal into their respective uses, such as steam coal and metallurgic coal. Abbreviations are also given in Table 1, and are simply a quick way to refer to one type of coal over another for those who are familiar with the many different groups.

Table 1. ASTM Coal Rank ${ }^{9}$

\begin{tabular}{|c|c|c|}
\hline Class & Group & Abbreviation \\
\hline Anthracitic & Meta-Anthracite & ma \\
\cline { 2 - 3 } & Anthracite & an \\
\cline { 2 - 3 } & Semianthractie & sa \\
\hline Bituminous & Low Volatile & Ivb \\
\cline { 2 - 3 } & Medium Volatile & mvb \\
\cline { 2 - 3 } & High Volatile A & hvAb \\
\cline { 2 - 3 } & High Volatile B & hvBb \\
\cline { 2 - 3 } & High Volatile C & hvCb \\
\hline Subbituminous & Subbituminous A & subA \\
\cline { 2 - 3 } & Subbituminous B & subB \\
\cline { 2 - 3 } & Subbituminous C & subC \\
\hline Lignitic & Lignite A & ligA \\
\cline { 2 - 3 } & Lignite B & ligB \\
\hline
\end{tabular}


For CBM production, reservoir engineers prefer bituminous coals. Coal in this class has matured to retain more gas and also generally has the sought after mechanical properties allowing for the greatest potential of being a successful reservoir. This concept is also illustrated in Figure 4.

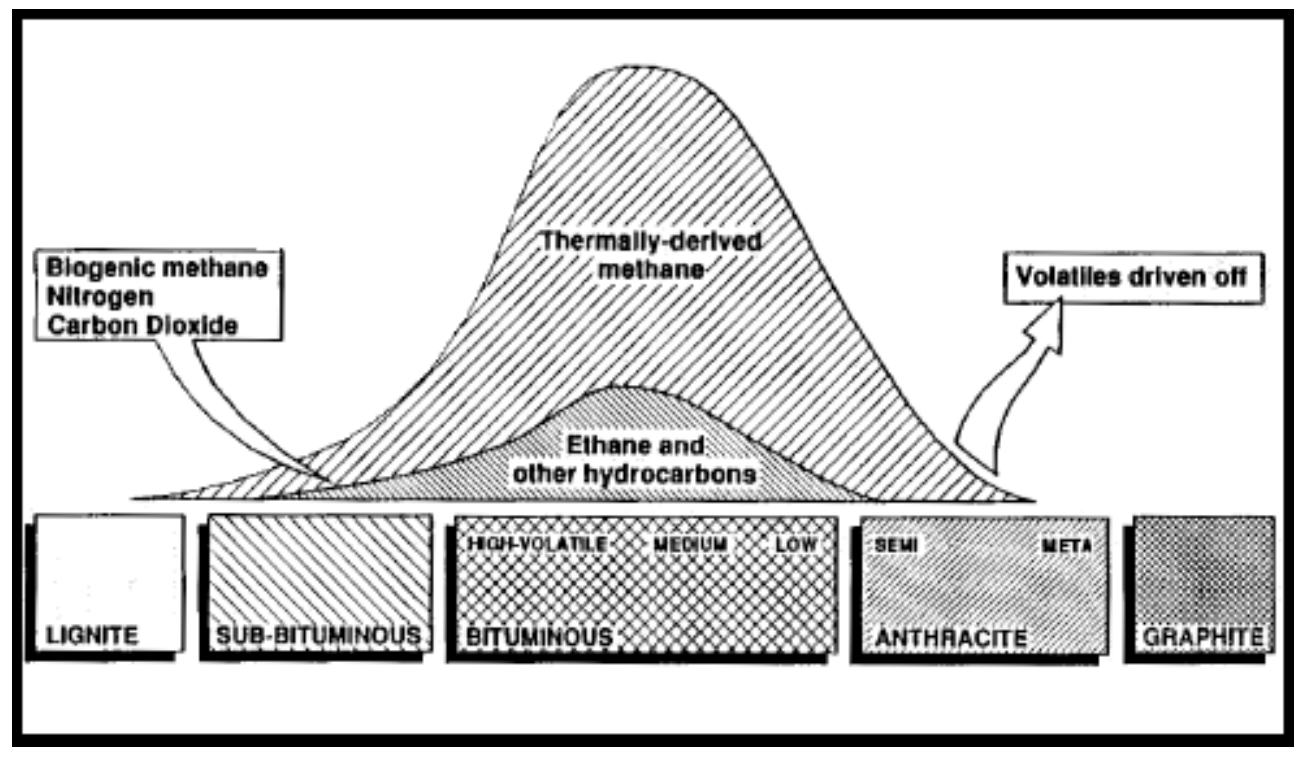

Figure 4. Gas Generation in $\mathrm{Coal}^{7}$

The production and technologies employed in the coalfields have been adapted into oilfield techniques over the years, none more so than in the CMB subsector of petroleum engineering. Many technologies have become merged. Furthermore, the importance of both natural and domestic resources is often recognized together and thus the production of coalbed methane from large coal deposits is important and relevant. The production of coalbed methane in a short time has become an important industry, providing an abundant, clean-burning fuel at a time when concerns about pollution and fuel shortages preoccupy the thoughts of many. In fact, approximately fifteen countries around the world have plans that either greatly rely on or intend to rely partially on coalbed methane. 


\subsection{Sorption Processes}

Due to the nature of CBM and its development in coal seams, the primary recovery method is by adsorption. Rather, the gas is not collected within the coal by absorption but instead is a created and found by the molecular processes that produce the methane. This process is similar to surface tension, and thus can be described by isotherms. The isotherms are functions of adsorbate on the adsorbent as a function of pressure and temperature. In this case the adsorption capacity of coal is defined as the volume of gas adsorbed per unit mass of coal. In typical units, it is generally expressed in standard cubic feet (SCF) of gas per ton of coal. The capacity of the gas to adsorb depends on the rank and quality of coal as previously mentioned. However, the range is usually between 100 to $800 \mathrm{SCF} /$ ton for most coal seams found in the US ${ }^{12}$.

CBM reservoirs are also unique to their conventional counterparts for other reasons aside from the adsorption process. For instance, gas produced from coalbeds is frequently higher in methane content than that of conventional reservoir gas. This is because the ethane and other heavier hydrocarbons are more strongly absorbed than methane. This is a result, as is implied, of the sorption processes. The difference in the mechanics of gas storage for conventional and unconventional reservoirs is a function of how the void spaces in the rock are occupied. In conventional reservoirs, the free gas is trapped between sand grains. In unconventional reservoirs such as coalbeds, the

methane is trapped along the coal surface by adsorption to the micropores ${ }^{8}$. (There is also a trivial amount of gas in the natural cleat system and the water which occupies those cleats.) As water is removed from the reservoir via the cleats, the hydrostatic pressure of the reservoir is lowered and eventually, the adsorbed gas is released at a critical desorption pressure, Pc.

Langmuir isotherms govern CBM production. And although the assumptions that the Langmuir curves are based upon are ideal circumstances, the curves still allow with 
great precision for the analysis of the CBM production. These Langmuir equations fit the absorption data of CBM and have since become exclusively used in the CBM process and are a universal practice in the industry. Also, as the coal's depth (and pressure) increases, the adsorption capacity of the coal also increases. Hence, the gas content, Gc, can be calculated with the Langmuir volume constant (Scf/ton) and the Langmuir pressure constant (psia) and the known pressure of the formation.

$$
G_{C}=\frac{V_{L} P}{P_{L}+P}
$$

\subsection{Porosity and Permeability}

As mentioned, the permeability of the coalbed is quite low. The porosity of the coalbed is deceiving, though. Often, the porosity is in the range of 0.1 to 10 percent, but yet coal can hold quite a bit of methane for a reservoir with such a low porosity. This is in part due to the dual porosity system that coal exhibits.

The dual porosity system is comprised of macropores, which is where the methane is stored, and the cleat and natural fracture systems. The cleat systems are essential for the transportation of water and methane, ultimately leading into the wellbore, but are relatively unimportant for actually finding and storing methane. The storage space of the cleats and other natural fractures typically contain water, free methane, and methane dissolved in water ${ }^{17}$. Thus it is after the dewatering process that true methane production begins.

Even though coal's porosity may range from 0.1 to 10 percent, the coal may have a storage capacity for methane in the mircopores equivalent to that of a 20 percent 
porosity sandstone with 100 percent gas saturation at the same depth ${ }^{17}$. Hence, a large amount of methane can be stored in the coalbed and thus its low porosity can be deceiving.

Permeability, while related to porosity, is not the same thing. In fact, the permeability of a formation is likely a more important physical aspect of the reservoir than is its porosity. Permeability is most directly related to the coal's natural system of cleats and fractures. Although a coalbed can exhibit a good porosity, it must also be of good permeability in order to be economically producible.

Unfortunately, the permeability can often be a difficult parameter to accurately estimate. It is only estimated by the experienced reservoir engineer by the analysis of the natural fracture systems, the interactions between the face and butt cleats, the degree and size of natural cracks, water saturation, depth of the rock, and in-situ stress $^{14}$.

One of the main reasons that the permeability plays such an important part in the production of CBM is because of the two phase flow regime that is displayed. Absolute and effective permeability are critical to understanding and determining the two phase flow regime, and eventually separate the gas and water from one another. The effective permeability is the ability to preferentially flow or transmit a particular fluid when other immiscible fluids are present in the reservoir. Absolute permeability is the measurement of the permeability conducted when a single fluid or phase is present in the rock ${ }^{14}$. According to the Langmuir isotherms, more gas can be absorbed as pressure (and hence depth) increases. However, producing that gas becomes more difficult as increased depth means increased formation pressure and lower permeability. 
The cleat system of the coal is directly proportional to the permeability - as the number of cleats per unit volume of coal increases, so improves the coal's permeability. Cleat aperture opening as well as the length and continuity can also impact the permeability. However, too high of a concentration of cleats can cause the coal to be brittle and may result in difficulties when completing the well, specifically when fracturing.

The directions of the butt and face cleat system has a significance in the orientation and spacing of horizontal wells and ideally, any horizontal lateral would be orientated perpendicular to the face cleats to intersect the most joints and to increase drainage area. Another way of conceptualizing this is to note that the horizontal well is able to connect (through the low permeability direction) the high permeability face cleats. Wells drilled perpendicular to the face cleats are reported to produce 2.5 to 10 times more gas than non-perpendicular wells ${ }^{16}$. However, when hydraulic fracturing is to be implemented, this design may change, as the hydraulic fractures are used to connect the high permeability face cleats instead of the lateral well.

\subsection{Gas Flow}

Coalbed methane is unique to other forms of natural gas because of its unconventional status. That is, plays are relatively new and less understood. They require newer technologies to economically produce and are often characterized by low permeabilities. In the 1970s, the United States government defined any tight gas or unconventional reservoir as one in which the expected ratio of permeability to gas flow would be less than $0.1 \mathrm{mD}$. This definition was a political definition that has been used to determine which wells would receive federal or state tax credits for producing gas from unconventional plays ${ }^{21}$. 
In reality, the definition of an unconventional reservoir is a function of many physical and economic factors. Most are characterized by low permeability and follow Darcy flow. Darcy's Law relates the physical factors contributing to the flow regime of the gas.

$$
q=\frac{k h\left(P-P_{w f}\right)}{1422 T \ln \frac{r_{e}}{r_{w}}-.75+s}
$$

Hence, a namely difference between conventional and unconventional reservoirs is the actual mechanism of the gas flow itself. As gas flows though the formation to the wellbore, additional mechanisms of gas diffusion through the micropores of the coal matrix are involved. The mass transport depends upon the methane concentration gradient across the mircopores as the driving force ${ }^{8}$. Once the gas flow stumbles upon a cleat or fracture, the gas will flow according to Darcy's law as it would in a conventional reservoir. In contrast, conventional reservoirs depend almost entirely on pressure gradients for their flow.

Initial conditions inside the reservoir are such that the cleats are fully saturated with water. In relation to the Langmuir isotherm which will govern the production, the cleats are under saturated with respect to the gas. Therefore, as water is removed (produced), the pressure is lowered and the desorption process is initiated. The time period that is required for the pressure to reach this point is called the infinite acting period $^{8}$ and is illustrated as Phase I in Figure 5.

As the reservoir continues production, a two-phase flow regime near the wellbore is seen. As this two-phase flow continues, pressure drops within the coal seam continue to increase. This, Phase II flow, causes the gas to permeate the reservoir in greater quantity. Eventually, boundary effects are seen. When one boundary (and not 
all of the boundaries) is seen, the flow period is known as the transition state ${ }^{10}$. Eventually, Phase III occurs where all boundaries are acting on the flow and the reservoir begins producing at a pseudo-steady state.

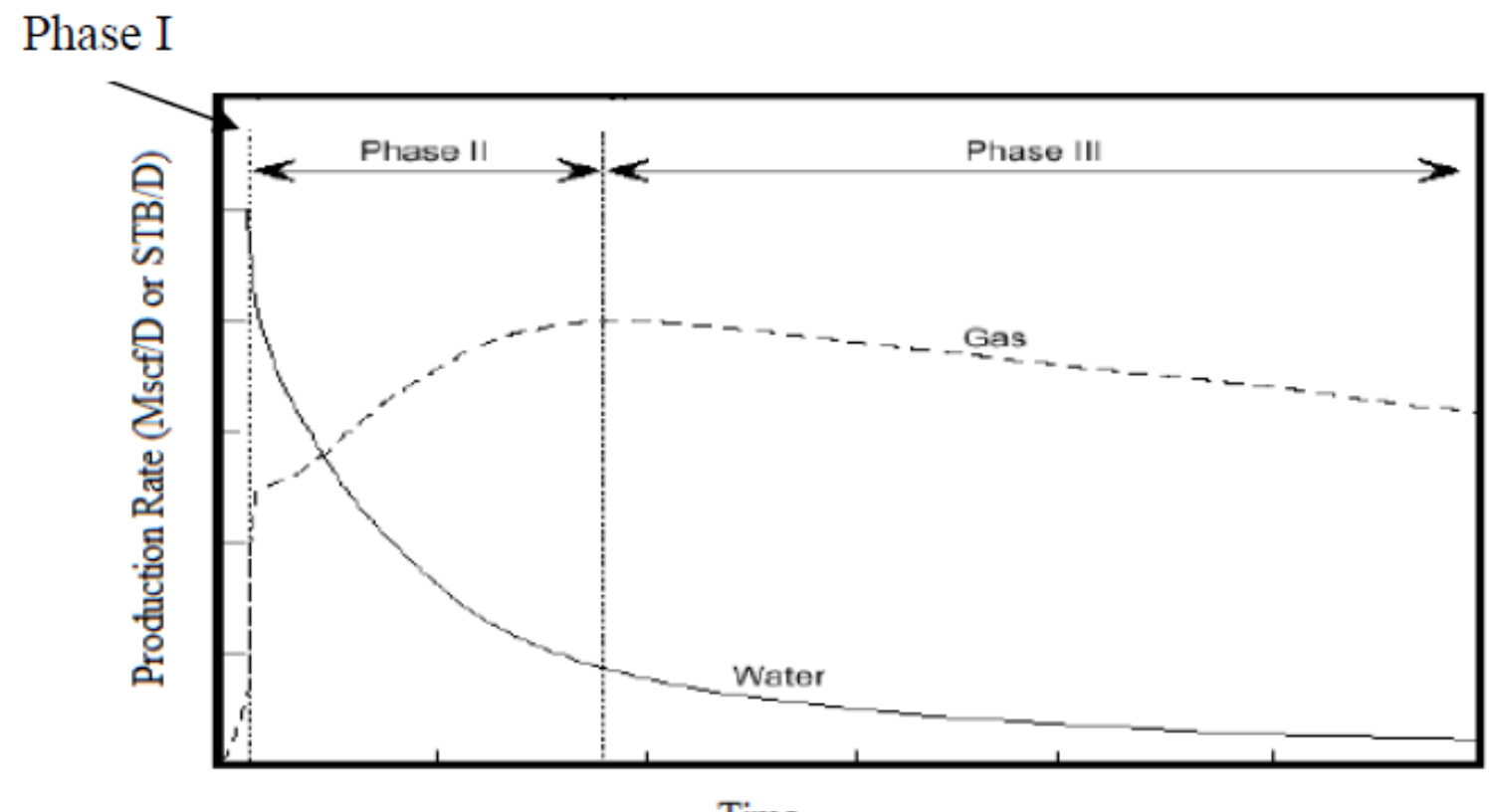

Figure 5. Production Decline for Vertical Wells ${ }^{10}$

\subsection{Horizontal Wells}

Horizontal wells have become an increasingly practiced method in order to recover more hydrocarbons from the reservoir which is being produced. This enhanced oil recovery (EOR) method continues to gather popularity as the price of oil increases. However, the technology is not new. The technology was first used in 1891 when the first patent was acquired, acknowledging the idea that special equipment could be placed in the bottom of a vertical well and used to drill horizontally ${ }^{2}$. A directional (or horizontal) well can be particularly impressive to the increased production for many reasons. 
By definition, a directional well is one that has been drilled to intersect a potentially productive formation and does not exit that formation for the duration of the drilled footage. The directional well is completed by drilling a conventional vertical well initially, and then at a determined "kick off" point (KOP), the well deviates from the vertical so that the well bore enters the formation roughly parallel to the formation.

Horizontal wells can also be particularly important in the production of coalbed methane (CBM) reservoirs. Namely, they can be economically advantageous because of their ability to connect the high permeability cleat systems of the coalbed. The coal seam develops naturally over time with two types of cleats - face cleats and butt cleats. The face cleats are the primary form of coal seam permeability. In fact, the permeability of the coal matrix is negligible by comparison ${ }^{24}$. The two types of cleats are typically at approximately right angles to one another. The face cleats are continuous and provide paths of higher permeability while butt cleats are noncontinuous and end at face cleats. These face cleats can be connected to allow the higher flow rate of gas by the placement of an effective, perpendicular horizontal wellbore.

Horizontals are typically placed normal to the highest permeability zone in the formation. In CBM reservoirs, this is also perpendicular to the face cleats. Hence, under this design, there is greatly improved production due to the connected natural fracture network ${ }^{5}$. The well dewaters the reservoir significantly quicker, and thus accelerates the gas production as well, when compared to a traditional vertical well.

Horizontal wells do, however, have limitations and therefore as only applicable when the engineers carefully decide upon their use in a reservoir. For instance, in specific types of rock formations, horizontal wells may have a greater potential to collapse $^{3}$. This can happen, for example, in wet sand formations, due to the instability 
of the wellbore between drilling and cementing procedures. However, in coalbed formations, this is not a concern.

Other concerns regarding horizontal wells which can be found in almost all reservoir types include two main problems. The first problem with which the reservoir engineer must consider is the large wellbore storage effects created. Horizontal sections are often designed to extend for thousands of feet and cannot be isolated from transient flow. (Transient flow is any flow which velocity and pressure changes are occurring over time, and by comparison, wellbore storage effects can alter these expected effects, creating an unknown production data set.) The next complexity faced commonly when utilizing horizontals is the very nature of the transient flow itself. Once wellbore storage effects are stabilized and accounted for, three flow regimes can occur. In a conventional vertical well, a radial-flow regime would be expected.

The three flow regimes that will occur, sequentially, as dictated by the horizontal after the wellbore storage effects have begun to diminish are early-time pseudoradial flow, intermediate-time linear flow, and late-time pseudoradial flow. The first is radial flow occurring in a vertical plane toward the wellbore. This is most easy to see by noting a plateau on the derivative curve on a log-log plot. The flow has become known as early-time pseudoradial due to the permeability anisotropy, which actually causes an elliptical flow pattern. This is particularly important for coalbed methane reservoirs, as the permeabilities differ in each direction. Likewise, if the formation height is small, or if $\mathrm{k}_{\mathrm{v}} / \mathrm{k}_{\mathrm{H}}$ is small, this early radial flow may not be present ${ }^{6}$.

The next flow regime begins after the transient flow reaches the upper and lower boundaries of the producing zone and flow becomes linear toward the well within the horizontal production plane. The derivative curve at this point now produces a line with slope equal to $1 / 2$. The third and final flow regime, late-time pseudo-radial flow, occurs after the transient flow acts upon an area far enough from the well that it causes 
the flow to become radial again. However, this should occur in the horizontal plane as well. The derivative curve then shows a second plateau as seen below.

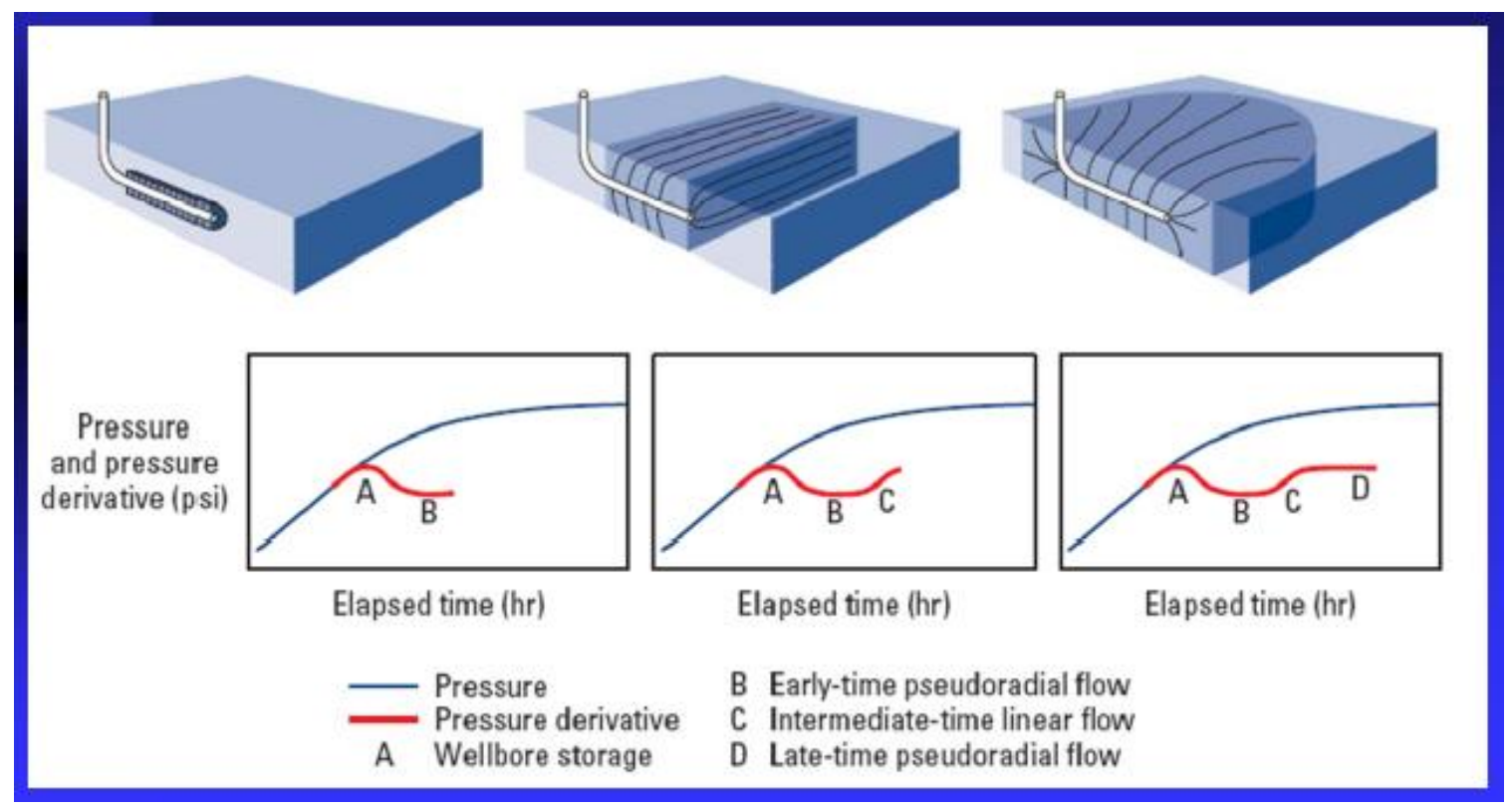

Figure 6. Flow Phases for a Horizontal Well ${ }^{7}$

Logically, the side boundaries of the drainage region are not the only factors in determining the shape factor of the well. Particularly in horizontal wells, the top and bottom reservoir boundaries can also have substantial influence the well productivity. Again, this can be particularly important in CBM reservoirs as permeability in the vertical direction is less than that of the horizontal plane. A horizontal well shape factor therefore also depends upon drainage area shape, well penetration, and dimensionless well length. The research that follows in this report takes careful consideration of these factors. The ratio of the reservoir's length (that in the direction of the lateral well) to the length of the lateral well is defined by $L / X e$. The ratio of the reservoirs' lengths to widths being examined has been set at 2 . That is, $\mathrm{Xe} / \mathrm{Ye}$ is always at a two to one ratio. These shape-related skin factors for horizontal wells, $s_{C A}$ are tabulated in the table below ${ }^{12}$. 
Table 2. Shape Related Skin Factors for Horizontal Wells

\begin{tabular}{|c|c|c|c|c|c|}
\hline \multicolumn{7}{|c|}{ L/Xe (Xe/Ye = 2) } \\
\hline $\mathbf{L}_{\mathbf{D}}$ & $\mathbf{0 . 2}$ & $\mathbf{0 . 4}$ & $\mathbf{0 . 6}$ & $\mathbf{0 . 8}$ & $\mathbf{1}$ \\
\hline 1 & 4.425 & 4.578 & 5.025 & 5.42 & 5.86 \\
\hline 2 & 2.84 & 3.01 & 3.13 & 3.26 & 3.46 \\
\hline 3 & 2.38 & 2.45 & 2.61 & 2.73 & 2.94 \\
\hline 5 & 1.982 & 2.02 & 2.15 & 2.31 & 2.545 \\
\hline 10 & 1.74 & 1.763 & 1.85 & 1.983 & 2.198 \\
\hline 20 & 1.635 & 1.651 & 1.72 & 1.839 & 2.04 \\
\hline 50 & 1.584 & 1.596 & 1.65 & 1.762 & 1.959 \\
\hline 100 & 1.572 & 1.582 & 1.632 & 1.74 & 1.935 \\
\hline
\end{tabular}

Some type curves have previously been developed for predicting horizontal well production. Typical dimensionless groups were created. The parameters allow for the performance prediction of horizontal well production in unconventional finite and infinite reservoirs ${ }^{9}$.

$$
\begin{gathered}
t_{D A}=\frac{0.001055 k_{H}}{\varphi c_{t} \mu A} t \\
G_{p D A}=\frac{36 T}{h \varphi c_{t} A P_{p}} G_{p}
\end{gathered}
$$

In these equations, the dimensionless cumulative production and time is based on the drainage area. Figure 2 illustrates the effects of horizontal well penetration on long term production behavior of the horizontal wells. Figure 3 compares the performance of a horizontal well in a square drainage area versus a rectangular drainage area when the direction of the well coincides with the longer side of the rectangle. In this research, rectangular reservoirs are studied, as mentioned, at a two to one length to width ratio. The drainage area for a horizontal well approaches an elliptical shape, resulting in improved performance of the horizontal well as compared to a square 
drainage area $^{13}$. Therefore, the horizontal well penetration and the geometry of the drainage area greatly affects the type curves.

\subsection{Horizontal Type Curves}

Type curves for horizontal wells differ from those relating to vertical wells. This is, in part, due to the different drainage shapes and flow regimes seen by the producing well. Two dimensionless groups are used, and often, the type curve is broken up into early-time and late-time production.

Two sets of dimensionless groups are used, including $q_{D} v s . t_{D}$ and $q_{D} v s . t_{D} \times L_{D}$. The reason that two sets of dimensionless criteria are used stems from the fact that the production data is broken up into early and late-time, as mentioned. By breaking the production data into two sets, and developing two curves, one can see the comparisons between two sets of data more clearly, and neglect the effects of the flow regimes which cause variations in the curves. By multiplying $t_{D}$ by $L_{D}$, the effects of the elliptical flow on the curve are reduced. Drinkard (2009) created type curves illustrating this fact.

These type curves, as provided by Drinkard, are for horizontal CBM reservoirs. Horizontal CBM type curves differ from vertical CBM type curves, as previously mentioned and coalbed methane reservoir type curves will be discussed in greater depth in section 2.8 of the report. Drinkard worked to create a set of usable type curves for horizontal CBM reservoirs. The research accounted for the different porosity matrices, horizontal well lengths, flow regimes, and assumptions generally associated with typical CBM reservoirs. Many of the reservoir characteristics used throughout the research were chosen in order to continue along the previous path. Hence, a reference to a standard, or base model, is implying a general CBM reservoir as defined in his work 


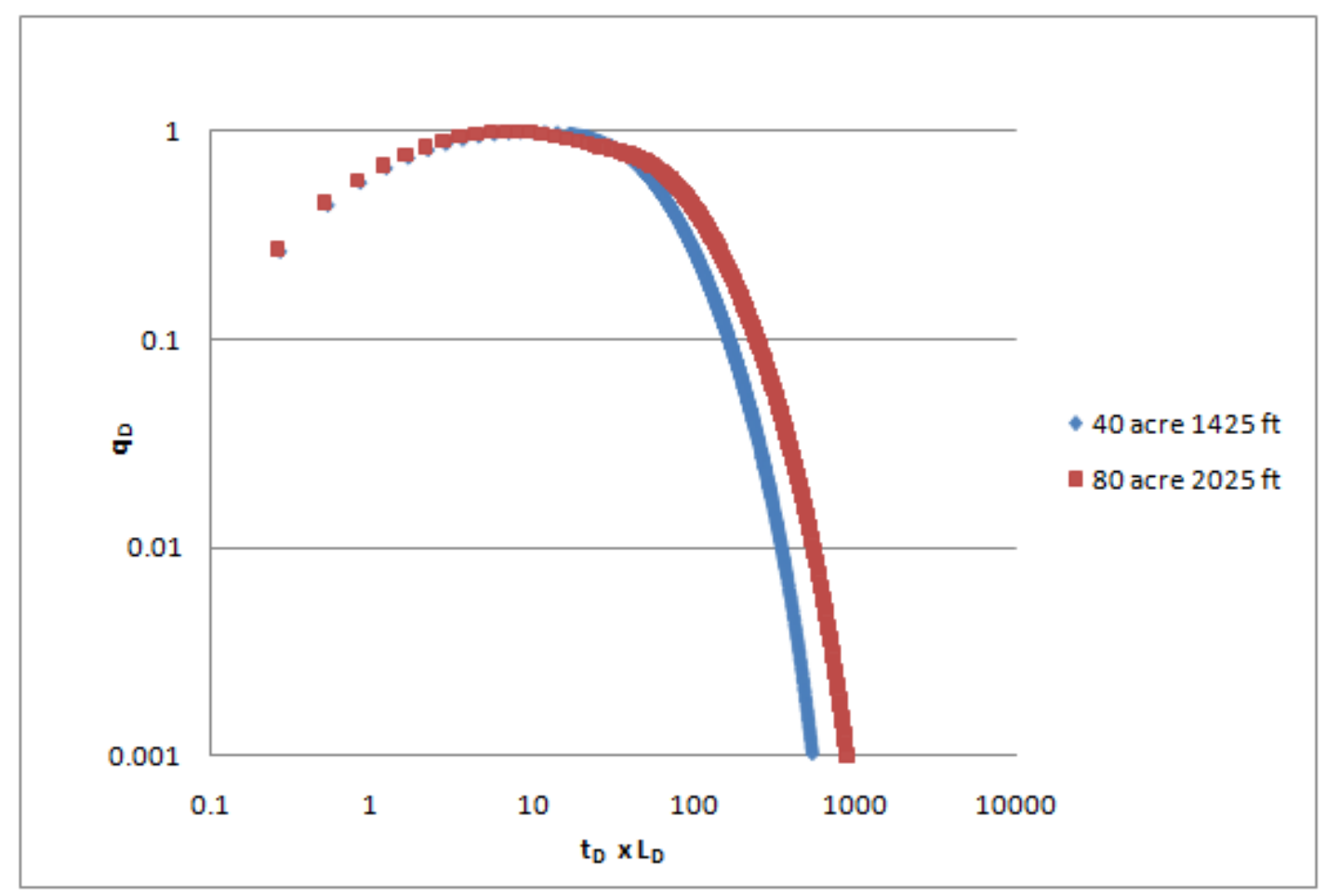

Figure 7. Early-time Production Type Curve for Horizontal Well ${ }^{23}$

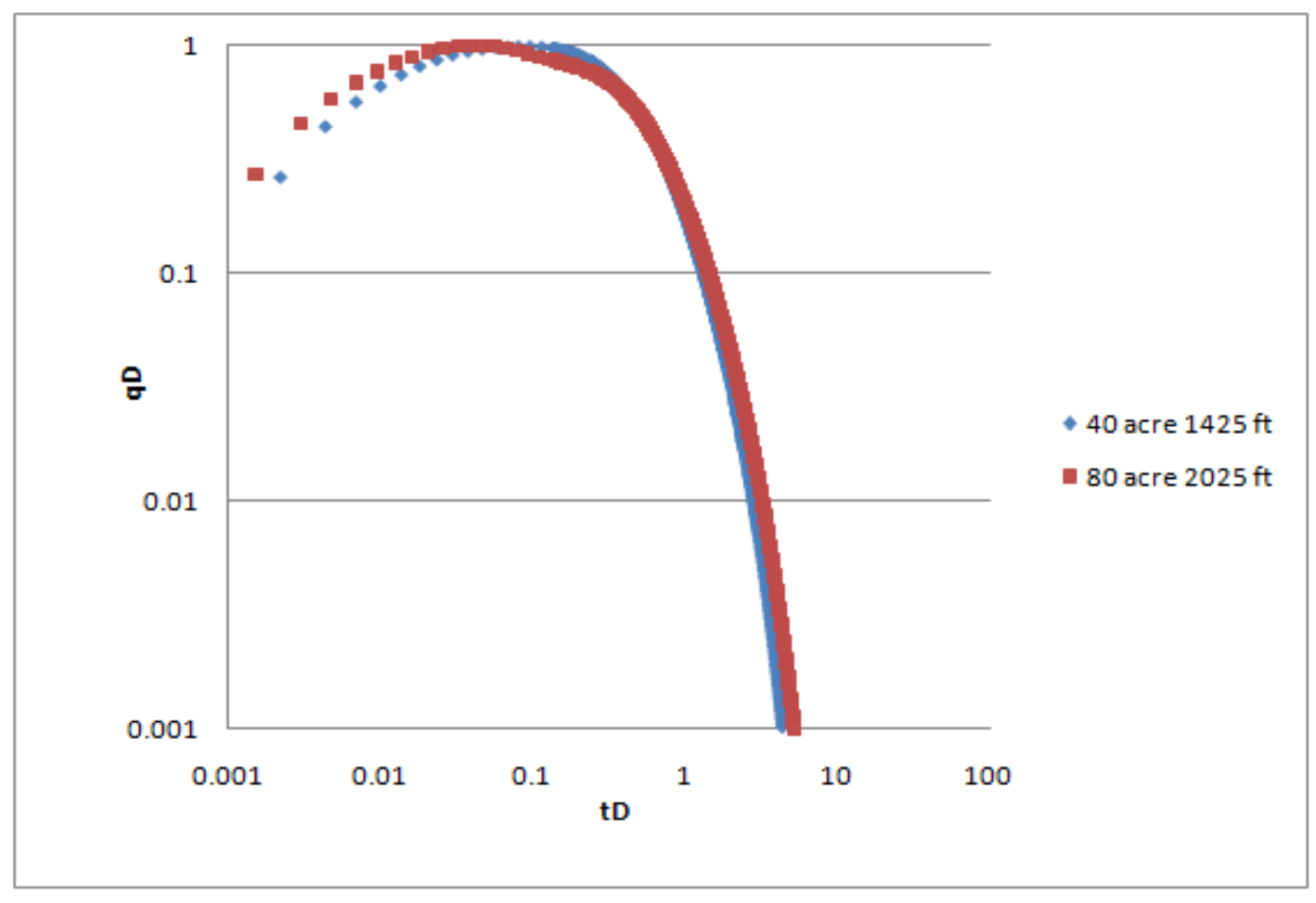

Figure 8. Late-time Production Type Curve for Horizontal Well ${ }^{23}$

19 


\subsection{Dimensionless Groups Used}

The base model will be evaluated slightly differently than the previously work performed by Drinkard (2009). Similar dimensionless groups will be used, however, this research will rely heavily on dimensionless time and dimensionless flow rate. Generally it is considered insufficient to have only one set of dimensionless parameters due to the different flow regimes in vertical wells ${ }^{23}$. In Drinkard's work, a dimensionless group was needed for the first phase (linear flow) up to the peak gas production and then a second dimensionless group once the next flow regime has been reached (elliptical). Once dimensionless flow rate and dimensionless time are established, it is necessary to determine dimensionless well length, as follows:

$$
L_{D}=\frac{L}{2 h} \frac{k_{v}}{k_{H}}
$$

Dimensionless well length can have a substantial impact on the production of the reservoir, and this aspect played great importance in the work of Drinkard. The "base model" which is sometimes referred to is the reservoir model with the characteristics that Drinkard used in his research.

Since $L_{D}$ is a function of both the reservoir length and the length of the horizontal, the drainage area is affected and thus production as well. Drinkard's investigation of this parameter is shown in Figures 9 and 10. Coalbed methane reservoir type curves also rely on other dimensionless criteria aforementioned. The impact of $L_{D}$ is unique to CBM horizontal wellbores. 


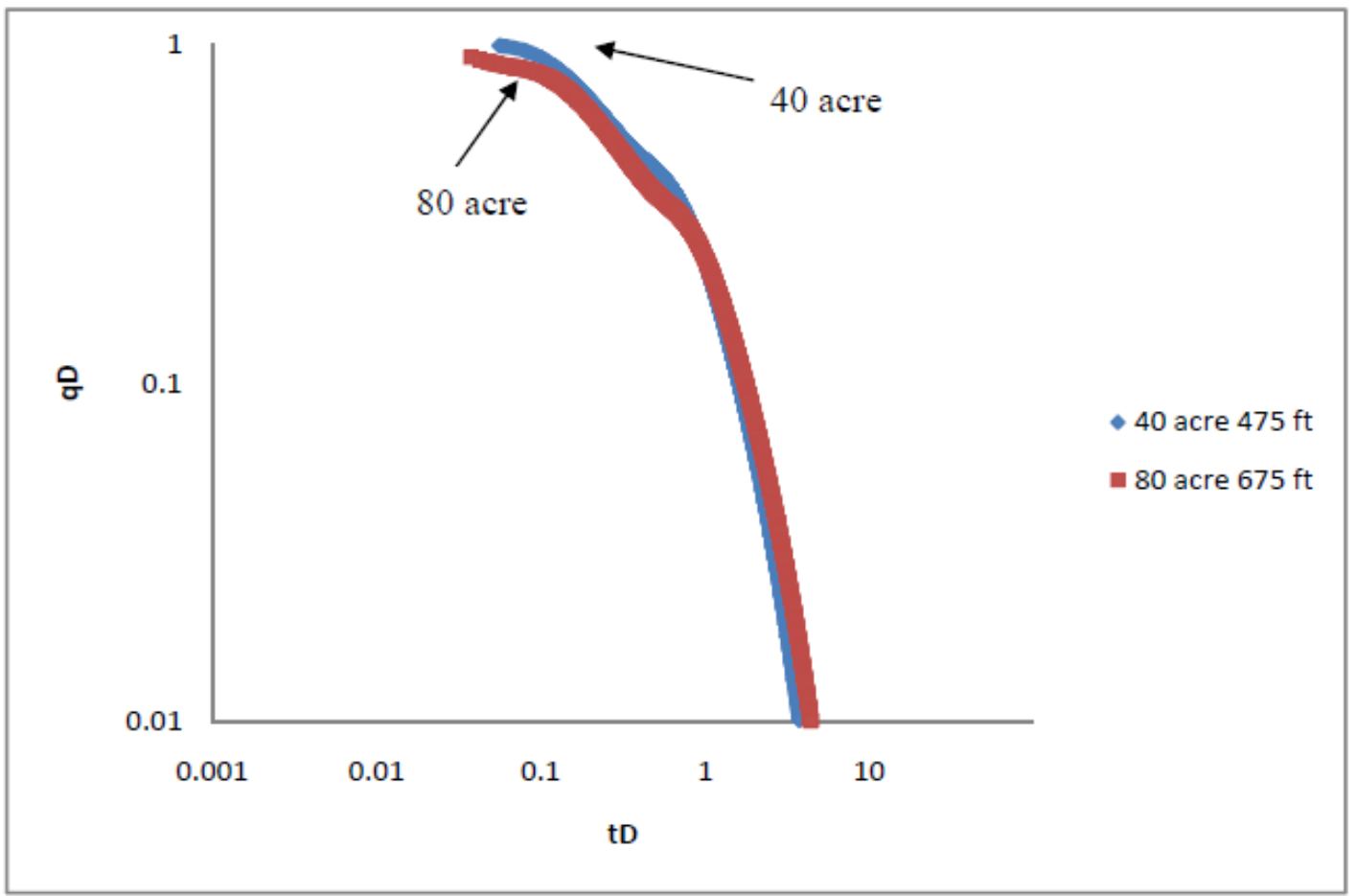

Figure 9. Impact of Drainage Area on the Type Curve when Comparing $L / X e=0.25$ for Late Production $^{23}$

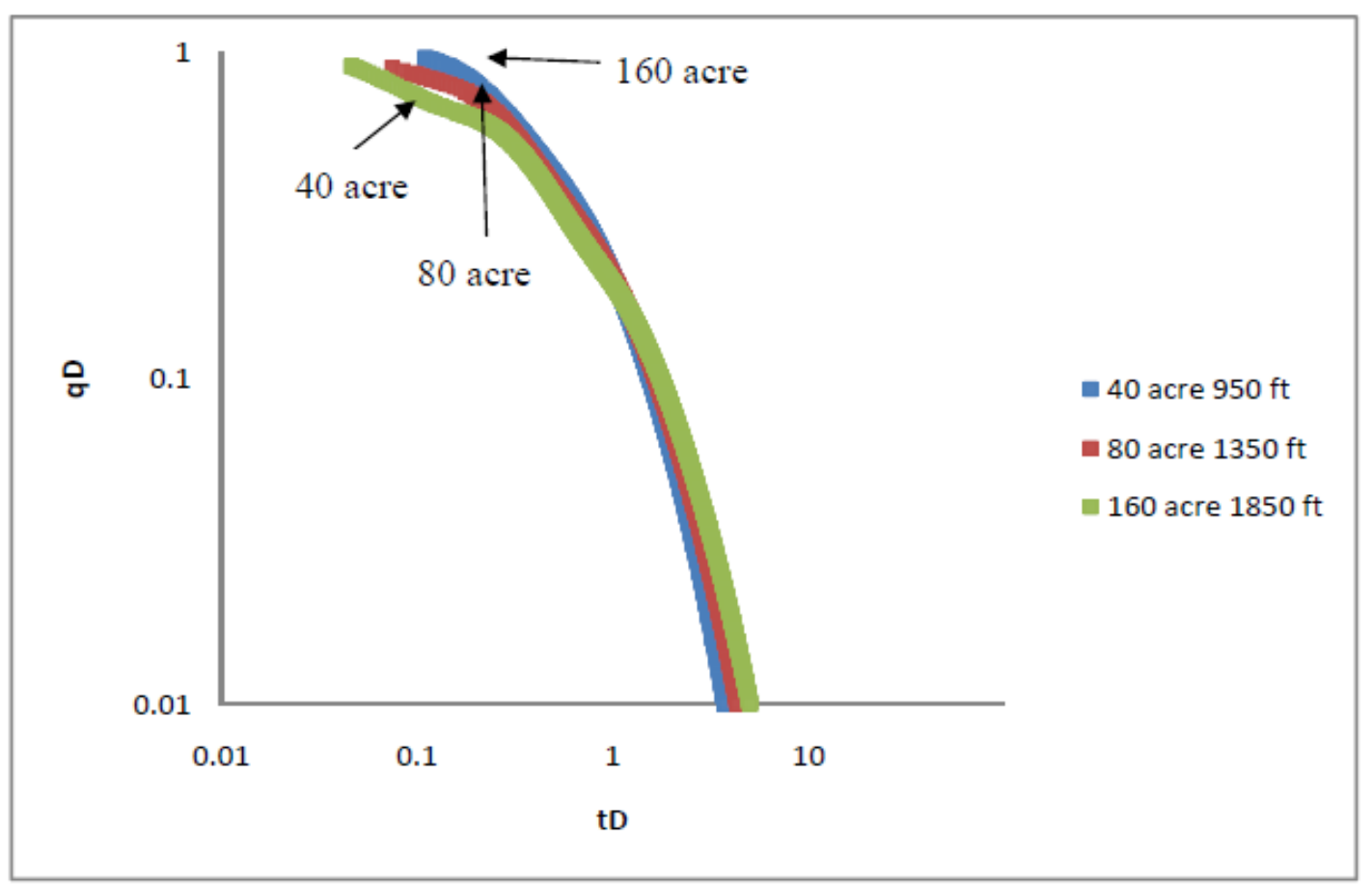

Figure 10. Impact of Drainage Area on the Type Curve when Comparing $\mathrm{L} / \mathrm{Xe}=\mathbf{0 . 5 0}$ for Late Production $^{23}$ 
The type curves that are created rely on the dimensionless parameters developed from equations 2.5, 2.6, and 2.7. The curves are also often broken up into early production and late production time as a result of the two flow regimes that the horizontal well encounters during production. Linear flow occurs until the peak production rate is reached. After the peak flow rate, late-time linear and pseudo-radial flows are seen. Study of the base model are inspected along these concepts, while the case study analysis involving the fractured reservoir are generally looked at with all the production history on one curve.

\subsection{Type Curves for Coalbed Methane}

Type curves are a long-known beneficial tool in the prediction of data in relation to the behavior of historically known data. The performances of reservoirs have often been evaluated by type curve analysis. These curves, however, do not replace reservoir engineering calculations altogether. Instead, they provide the engineer with an estimation as to how the well may produce throughout its life.

Type curves are used for conventional graphical curve matching in order to determine certain reservoir parameters that may be unknown when particular production history is already available or previously acquired. In fact, many type curves have already been established for vertical wells. Type curves are not as frequently found for the newer, horizontal technology, although some do exist.

In order to develop a type curve, the production history must be converted to dimensionless production values. Dimensionless flow rate and dimensionless time are found and then plotted in a logarithmic plot. An example of a type curve for a vertical

CBM well is shown in Figure $11^{25}$. The dimensionless groups are used to eliminate the 
effects of physically meaningful parameters such as gas rate, time, and reservoir areas, as conjectured in the Buckingham-Pi Theorem.

The dimensionless groups historically used have been most accurately found to provide match are:

$$
\begin{gathered}
t_{D}=\frac{q_{\text {peak }}}{G_{i}} t \\
q_{D}=\frac{q}{q_{p e a k}}
\end{gathered}
$$

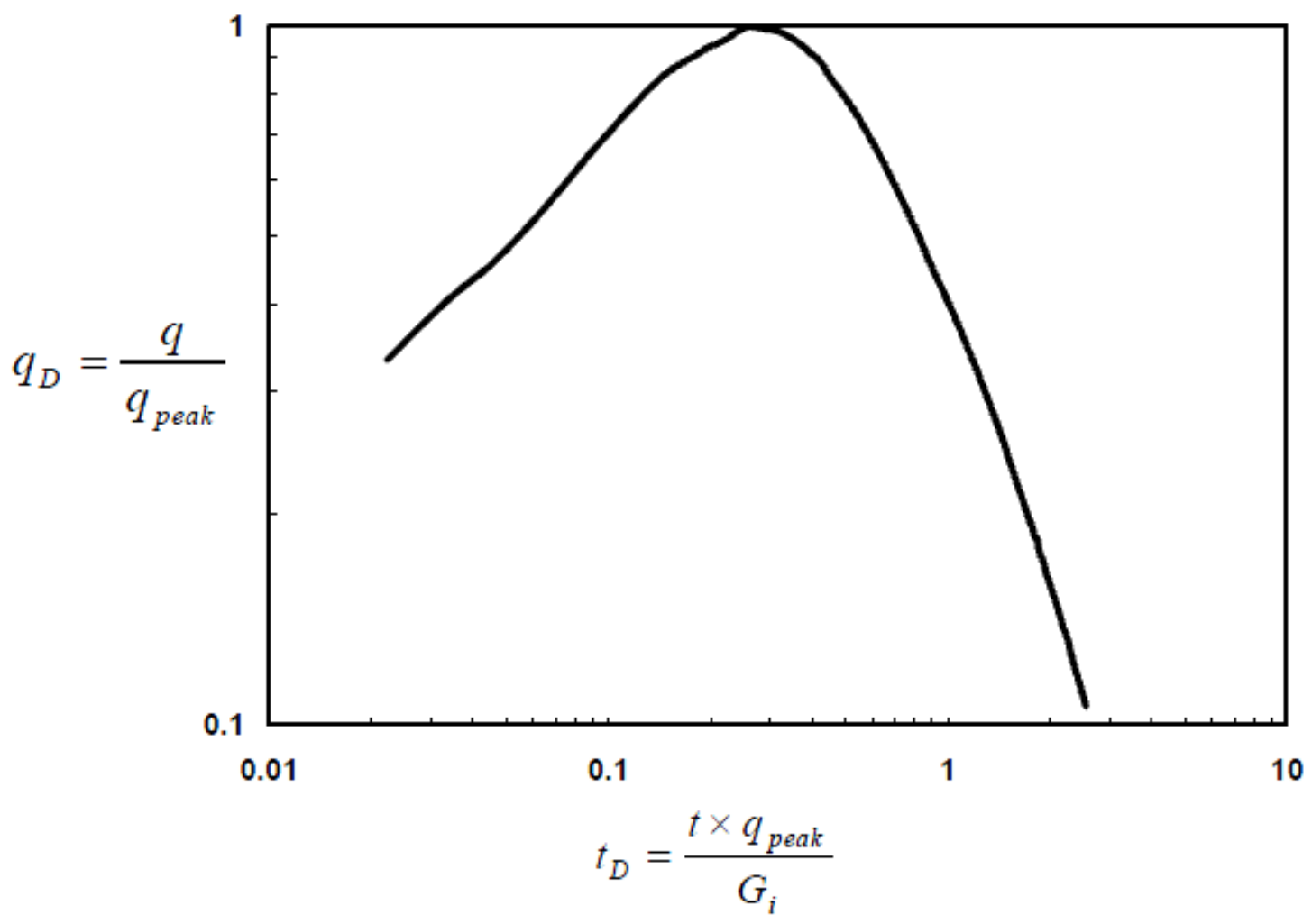

Figure 11. Traditional Type Curve for Vertical CBM Production ${ }^{25}$ 
In these equations, $q$ is the production flow rate of the gas and thus $q_{\text {peak }}$ is the maximum flow rate the reservoir is observed to produce. Time, $t$, is usually in days, and $G_{i}$ represents the initial gas in place, which can be calculated from the following equation.

$$
G_{i}=43560 A h G_{c}
$$

In the above equation, the area, $A$, is in acres, height in feet, and $G_{c}$, which is the gas content of the coal, is typically referred to in $\mathrm{Mscf} / \mathrm{ft}^{3}$, which standardizes the gas content as the reservoirs conditions act upon the gas differently than atmospheric conditions do. This constant is dependent on the type of coal in the reservoir.

In certain situations, type curves can be used to predict gas production for a prospective well if the dimensionless peak flow rate and initial gas content are known. Estimations have been developed, but it is not the nature of this research to investigate those methods. Rather, it is to create type curves by known (via simulation) data and thus known flow rate and gas content. Langmuir isotherms are useful in this analysis as well.

\subsection{Hydraulic Fracturing}

Hydraulic fracturing was first introduced for the stimulated recovery of hydrocarbons in United States in $1947^{13}$. The process occurs by loading proppant into the designated fracture points (perforations) within the wellbore, resulting in a twowinged, three-dimensional fracture extending outward from the well. The two wings are approximately 180 degrees apart and are positioned on each side of the wellbore. 
Thus, each wing is characterized by its half-length, $X_{f}$. Although slight design characteristics are unique to vertical and horizontal wells, the particular difference is the plane in which the fracture is oriented. In any case, the fractures are placed in such a fashion so that they are perpendicular to the least principal rock stress.

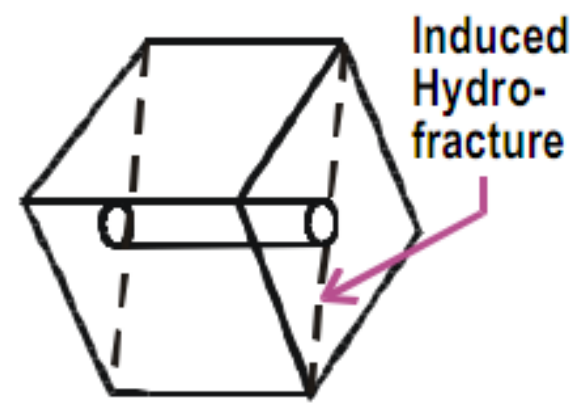

Figure 12. Created Fracture Geometry ${ }^{15}$

When creating a fracture, the method of pumping large volumes of fluids at (relatively) low rates allows for the potential penetration of the fracture to be very deep into the formation. It is not uncommon for a fracture half-length to be hundreds of feet in many cases. This technique (hydraulic fracturing, as opposed to other fracturing technologies) is currently the most widely used in the CBM industry ${ }^{15}$ as it allows for greater precision and design.

One principle benefit of the fracturing technology in coalbed methane reservoirs is the fact that the newly created spaces, although very small in width, provide a path for the water found in the reservoir to exit and thus result in quicker gas production. Since most of the gas in coal beds is in the adsorbed form, when the reservoir is put into production, the water in the fracture spaces is pumped off first leading to a reduction of pressure and enhancing the desorption of gas from the matrix ${ }^{20}$. This dewatering, along with other oilfield technologies, greatly increases production rates, often allowing for economic production. Although these man-made fractures are often on the scale of hundredths of inches, this is a substantial increase in the porous space found naturally 
in the coal seams. Hence, a greater overall effective permeability is created within the reservoir.

The design of the hydraulic fracture is mostly specified by the fracture halflength, fracture width, and fracture conductivity, which is the product of the fracture width and the fracture permeability. Fracture permeability is a consequent of the proppant and fluid used, and can be on the order of $10^{5}$ times the permeability of the reservoir. It is also important to take advantage of the increased permeability by designing the fracture such that it extends through the low permeability direction of the reservoir; that is, the fracture half-length runs through the low permeability zone so that natural face cleats can be connected for increased reservoir permeability.

\subsection{Numerical Models and Assumptions}

In order to eventually be able to develop accurate and reliable type curves for unconventional horizontal wells, numerical modeling will be needed in order to account for the large sets of data that would be needed for analysis. As it is, conventional decline curve methods cannot be used to predict CBM production due to the very nature of the unconventional complexities of the reservoir. It was previously noted that CBM reservoirs are produced by the interaction of gas desorption in the matrix the twophase flow as gas passes through the natural fractures. Numerical reservoir systems that account for the various mechanisms seen in CBM production can be used to gather these large sets of data.

This study continues upon the groundwork set previously in other research projects with pre-determined reservoir characteristics ${ }^{23}$. Thus, a known, base model for comparison study has been used in order to replicate known results. Of the information provided in the base model, specific key parameters may not have been available. 
When this was the case, a typical Monte Carlo simulation was performed to determine a reliable sense of those parameters and of the production potential of the reservoir. Monte Carlo methods are a class of computational algorithms that rely on repeated random sampling to compute their results ${ }^{19}$.

Of the several modeling tools available, Schlumberger Eclipse stands out as one of the most viable. Its easy-to-use interface and many numerical templates make it a logical choice to carry out the modeling. In particular, the Eclipse Office Suite provides a coalbed methane template. Although the CBM template has some limitations, it is still a very powerful and accurate tool. Perhaps most notably, the template simulates the reservoir as a single porosity. Although we know this is a simplified assumption of the actual dual porosity within the reservoir, it is able to incorporate the desorption process and still provide accurate results. The model therefore, requires an initial water saturation of 100 percent, as this represents the water in the cleat system, and not the micropores.

The Coalbed Methane template has other advantages as well. With the graphical user interface, the user can quickly manipulate the reservoir characteristics and save the template for later use and simulating. This is a great advantage over other software packages that require an input file that must be coded meticulously. The template also allows for the easy input of reservoir and rock properties, vertical and horizontal well configurations, aquifers, fractures, economic and simulation controls.

With the coalbed methane template, the user can set up a reservoir simulation model without knowledge of the simulator input files or keywords. It allows the user to set up models with relatively simplified geology to study advanced well completion designs with no mapping required. It can be used to study the comparative value of 
simple vertical completions, hydraulic fracture enhancements, and single or multilateral horizontal completions.

It should have been implied that the Eclipse software is a very powerful tool, and can in itself be complex. However, with practice and support from the User's Guide it can be easily used and understood. Each template has its exceptionalities. The Coalbed Methane template has the given outline as provided by the Schlumberger Eclipse Manual $^{22}$, as shown on the following page.

Certain parameters are known by default. Other inputs are optional and do not need to be entered into the model for the simulation to run properly. Of the more important inputs that are also optional, the initial coal gas concentration should be entered such that reservoir is modeled as closely as possible to the known (base) model. This parameter is governed by the Langmuir Isotherm and has already been determined. It is also important that the cleat system is fully saturated with water so that the desorption process does not start without the production of the well and the recording of the production time. The template assumes gas found within the coal matrix diffuses to the matrix-fracture interface and subsequently desorbs into the fracture network using a Langmuir Isotherm as a boundary condition. 
- Model Definition

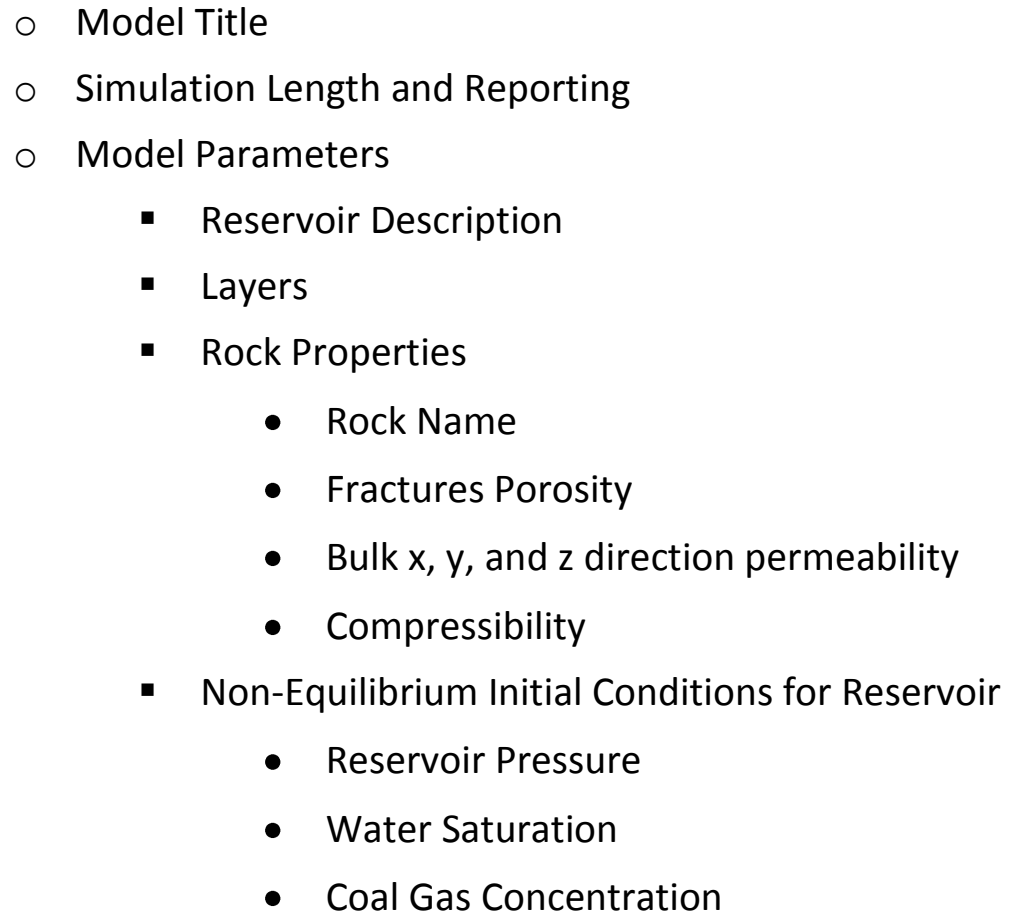

- Non-Equilibrium Initial Conditions for Reservoir

- Reservoir Pressure

- Water Saturation

- Coal Gas Concentration

- Aquifers

- Fractures

- Wells - Well Deviation

- Production

- Well Controls

- Perforations

○ Limits

- Bottom Hole Pressure

- Fluid Properties

- PVT Correlations

- Relative Permeability

- Coalbed Methane

- Fluid Properties

- CBM Properties Input

- User-Defined Langmuir Input

- Simulation Controls 


\section{OBJECTIVE AND METHODOLOGY}

The objective of this research is to aid in the development of type curves for unconventional, tight gas reservoirs. Specifically, production type curves for horizontal wells in coalbed methane reservoirs that have been hydraulically fractured for stimulation are to be made. In order to carry out this task, a series of steps are to be carried out. After proper care has been made to ensure the accurate working of the Eclipse software, the procedural steps include:

1. Input into Eclipse the reservoir model and begin determining how specific reservoir and fracturing characteristics will impact the production of the CBM reservoir.

2. Evaluate the impact and importance of parameters on the dimensionless type curves. Parameters include gas content, desorption time, permeability direction with respect to the horizontal wellbore, fracture half-length, fracture width, fracture conductivity, and number of fractures in the horizontal.

3. Development the production type curves for horizontal wells with hydraulic fractures in CBM reservoirs.

4. Develop a regression analysis for the parameters that show an effect on the type curve and/or peak production rate, such that future prediction of peak rate can be estimated.

\subsection{Defining a Basic Reservoir Model}

The base models were investigated in order to provide a needed level of accuracy. The parameters required to recreate the model were known and entered into the Eclipse model. Although the base model and the reservoir to be investigated in this 
research are similar, they are not the same. Certain differences do apply. However, by investigating the same base models as have been previously studied, it becomes possible to make sure that the software package is working properly, both at the computer's end and the user's end.

The base model used (as outlined by Drinkard's previous research) varies in length and width among two different reservoirs. However, the permeabilities and lateral placement are the same. Figure $13^{23}$ and Figure 14 provide the basic model, and specifically, Figure 14 shows the 80 acre model. Two basic reservoirs were studied, that of a 40 acre and that of an 80 acre area. These areas are in name only, and are actually of areas 41 and 83 acres, respectively. The reason that those specific numbers were used was due to the allowance of simply entering the length and width into the simulator at a ratio of 2 to 1 . These rectangular reservoirs were chosen because the drainage area shape $(\mathrm{Xe} / \mathrm{Ye})$, well penetration $(\mathrm{L} / \mathrm{Xe})$, and dimensionless well length $\left(\mathrm{L}_{\mathrm{D}}\right)$ are all major parameters in the production analysis development ${ }^{23}$.

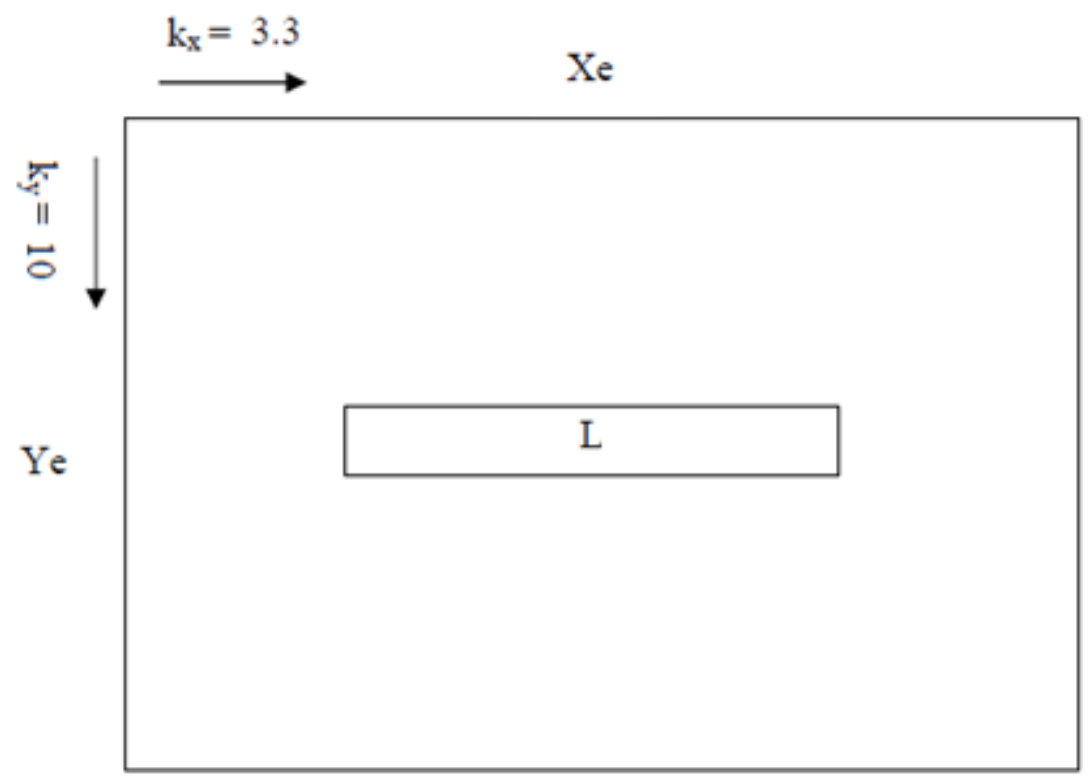

Figure 13. Original Model Shape 


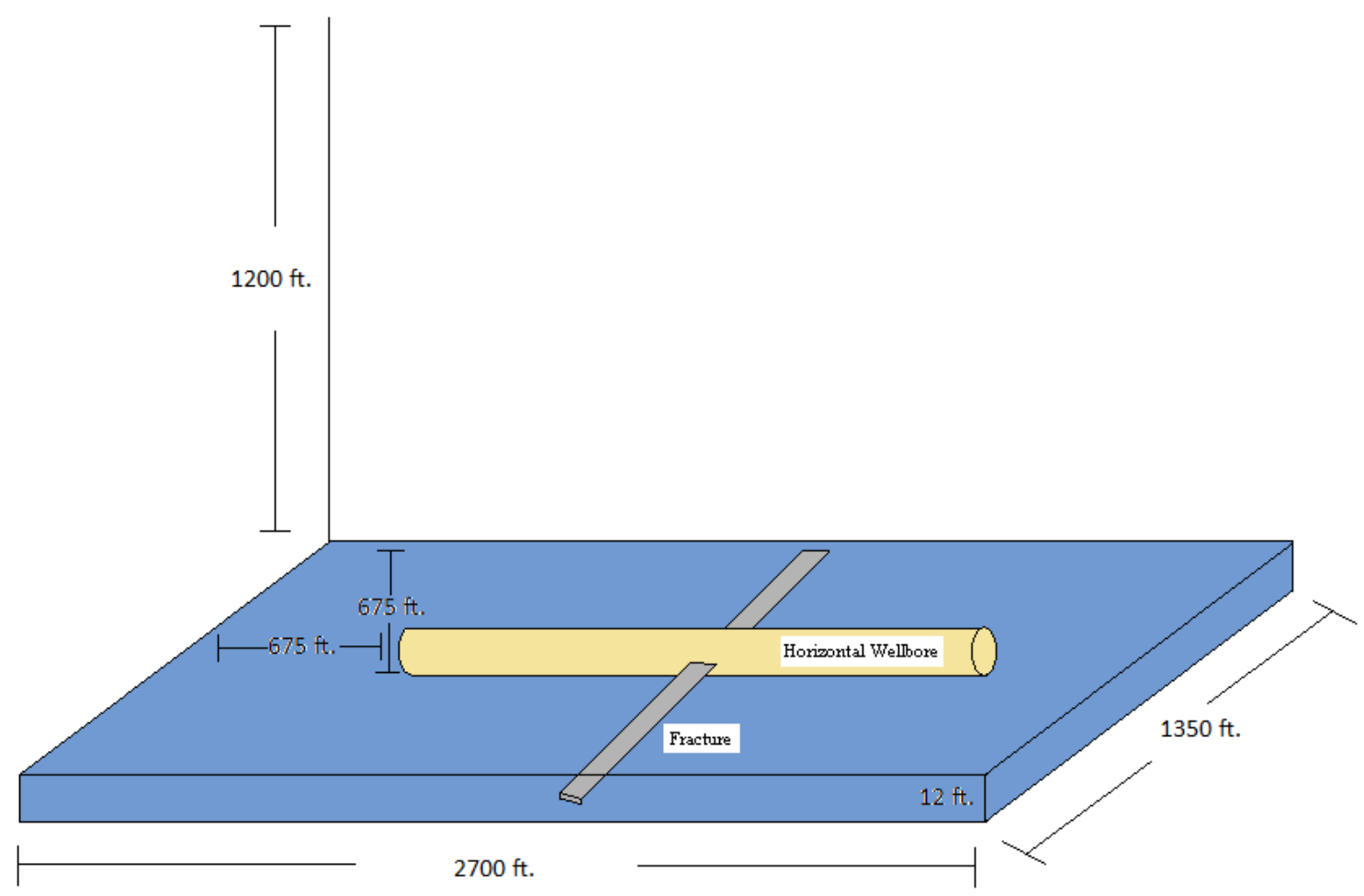

Figure 14. Three-Dimensional 80 Acre Model

\subsection{Model Characteristics and Variables to be Changed}

Different aspects of the reservoir needed to be evaluated one at a time in order to determine their impact on the type curves. Although different parameters were changed throughout the simulations, several were essentially kept constant. The ratio of the lateral length to the lateral reservoir length, L/Xe, was kept constant while changing other parameters. The ratio did take on two values, 0.25 and 0.50 . 


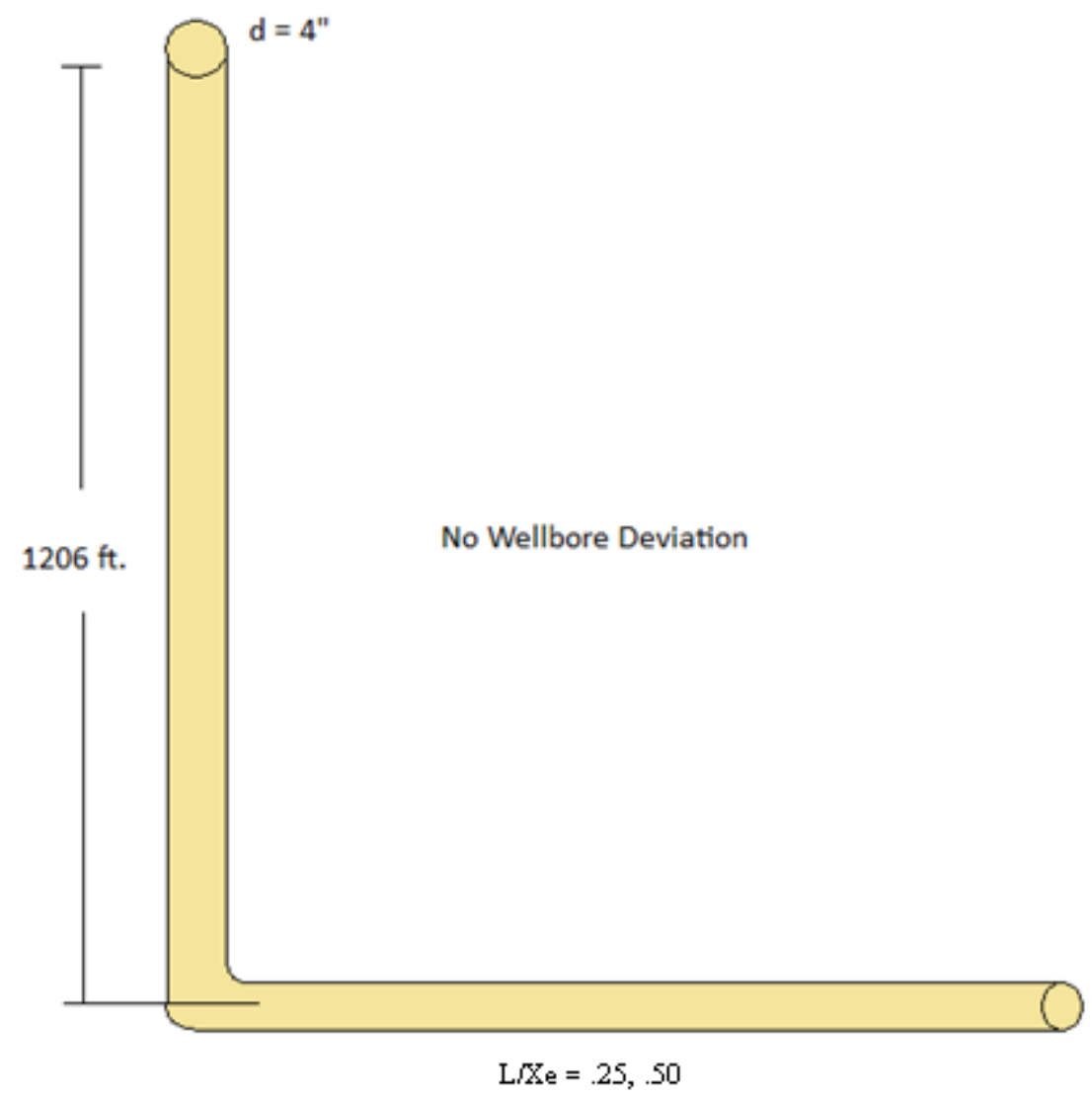

Figure 15. Horizontal Well Placement and Length Ratios

Critical desorption pressure was held constant at 350 psia. The permeability values for the horizontal plane were maintained at a 3:1 ratio, initially with the bulk $x$ permeability $=3.3 \mathrm{mD}$ and the bulk y permeability $=10 \mathrm{mD}$. These values are for the base model only, as the direction of the permeabilities needed to be swapped once hydraulic fracturing is initiated due to the logical direction of implemented fracs, as previously discussed. These permeabilities are also lowered by an order of magnitude to closer simulate CBM. Other permeabilities were also tested in the base model (still a 3:1 ratio) in order to replicate past results and gather a better understanding of permeability's effect on the type curves. The reservoir fracture porosity (natural fractures) was kept at a constant value of $1.7 \%$. Also, Langmuir pressure has a 
significant on the reservoir and was kept constant at 675.6 pisa. Table 3 provides the rest of the basic parameter inputs for the reservoir.

Table 3. Values and Ranges of Basic Reservoir Inputs

\begin{tabular}{|l|l|l|}
\hline Parameters & Range & Values Input \\
\hline Reservoir Shape & Rectangular & $2: 1$ Rectangle \\
\hline Area (Acres) & $41-83$ & 41,83 \\
\hline Reservoir Lateral Length (ft.) & $475-1350$ & $\begin{array}{l}40 \text { acre: } 475,950 \\
80 \text { acre: } 675,1350\end{array}$ \\
\hline Lateral Length Ratio (L/Xe) & $0.25-0.50$ & $0.25,0.50$ \\
\hline Permeability $\mathrm{x}, \mathrm{y}(\mathrm{mD})$ & $0.33-10$ & $(3.3,10),(10,3.3),(0.33,1),(1,0.33)$ \\
\hline Langmuir Concentration $\left(\mathrm{Mscf} / \mathrm{ft}^{3}\right)$ & $0.00728-0.01$ & $0.00278,0.01$ \\
\hline
\end{tabular}

\subsection{Case Study}

In order to develop the relationship between hydraulic fractures and the performance of CBM reservoirs drilled horizontally, a case study with specific parameters must be evaluated such that the type curves can be created. Reservoir characteristics will vary from simulation to simulation, but the basic input parameters are provided in Tables 4 and 5 below. Furthermore, a multiple regression analysis was performed after sufficient data had been collected to evaluate the impact of those parameters. 
Table 4. Input Values for Reservoir Simulation

\begin{tabular}{|c|c|c|c|}
\hline \multicolumn{2}{|c|}{ Input Parameters for Horizontal Model } & \multirow[t]{2}{*}{ Value } & \\
\hline Simulation Length & 25 Years & & \\
\hline Porosity & Single Porosity with Desorption & & \\
\hline Model Geometry & Single Layer Two Dimensional & & \\
\hline Model Parameters & $\begin{array}{l}\text { Two Phase Gas and Water } \\
\text { Non-Equilibrium Initialisation }\end{array}$ & & \\
\hline Gas Injection & None & & \\
\hline Reservoir Area & 83 Acre; Rectangular & & \\
\hline Production Limit & BHP Target (psia) & 80 & \\
\hline \multirow{4}{*}{ Reservoir Parameters } & $\begin{array}{l}\text { Depth (ft.) } \\
\text { Thickness (ft.) } \\
\text { Length, Ye (ft.) } \\
\text { Width, Xe (ft.) } \\
\end{array}$ & $\begin{array}{c}1200 \\
12 \\
2700 \\
1350 \\
\end{array}$ & 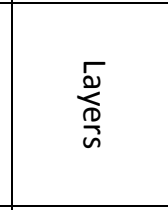 \\
\hline & $\begin{array}{l}\text { Fracture Porosity (mD) } \\
\text { Bulk X-direction Permeability (mD) } \\
\text { Bulk Y-direction Permeability (mD) } \\
\text { Bulk Z-direction Permeability (mD) } \\
\text { Coal Compressibility } \\
\text { Rock Density }\left(\mathrm{lb} / \mathrm{ft}^{3}\right) \\
\end{array}$ & $\begin{array}{c}0.017 \\
3.3 \\
10 \\
1 \\
1 \times 10^{-6} \\
89.63 \\
\end{array}$ & 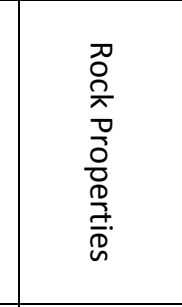 \\
\hline & $\begin{array}{l}\text { Reservoir Pressure (psia) } \\
\text { Water Saturation } \\
\text { Coal Gas Concentration }\left(\mathrm{Mscf} / \mathrm{ft}^{3} \text { ) }\right.\end{array}$ & $\begin{array}{c}650 \\
100 \% \\
0.00728 \\
\end{array}$ & 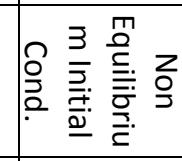 \\
\hline & $\begin{array}{l}\text { Reference Temperature }\left({ }^{\circ} \mathrm{F}\right) \\
\text { Gas Gravity } \\
\text { Reference Pressure (psia) } \\
\text { Maximum Pressure (psia) }\end{array}$ & $\begin{array}{l}90 \\
0.7 \\
650 \\
780 \\
\end{array}$ & 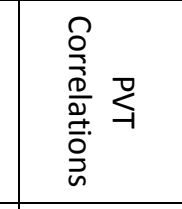 \\
\hline \multirow[b]{2}{*}{ Relative Permeability } & $\begin{array}{l}\text { Corey Gas Factor } \\
\text { Sgrw } \\
\text { Krg (Swmin) }\end{array}$ & $\begin{array}{l}2 \\
0 \\
1\end{array}$ & $\stackrel{\rho}{\sim}$ \\
\hline & $\begin{array}{l}\text { Corey Water Factor } \\
\text { Swmin } \\
\text { SwCrit } \\
\text { Krw (Sgrw) } \\
\text { Kr (100\% Sat) }\end{array}$ & $\begin{array}{c}3 \\
0.3 \\
0.3 \\
1 \\
1 \\
\end{array}$ & 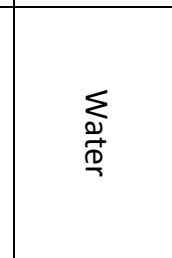 \\
\hline \multirow{2}{*}{ Coal Bed Methane } & $\begin{array}{l}\text { Gas Diffusion Coefficient ( } \mathrm{ft}^{2} / \text { day) } \\
\text { Gas Desorption Time (days) } \\
\text { Coal Re-absorption Factor }\end{array}$ & $\begin{array}{c}1 \\
30 \\
100 \% \\
\end{array}$ & 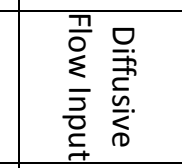 \\
\hline & $\begin{array}{l}\text { Critical Desorption Pressure (psia) } \\
\text { Langmuir Pressure (psia) } \\
\text { Langmuir Concentration (Mscf } / \mathrm{ft}^{3} \text { ) }\end{array}$ & $\begin{array}{c}350 \\
675.6 \\
0.0213 \\
\end{array}$ & 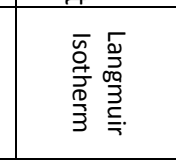 \\
\hline
\end{tabular}


Table 5. Fracture Values For Reservoir Simulation

\begin{tabular}{|lr|}
\hline Fracture Input & 80 Acre Model \\
\hline Fracture Alignment & Y-Axis \\
\hline Half-Length (ft.) & $300-500$ \\
\hline Width (in.) & $0.01,0.1$ \\
\hline Top of Fracture (ft.) & 1200 \\
\hline Bottom of Fracture (ft.) & 1212 \\
\hline X Center (ft.) & Varies \\
\hline Y Center (ft.) & 675 \\
\hline Permeability (mD) & 20,000 \\
\hline Porosity & $20 \%$ \\
\hline Perm Multiplier & 1 \\
\hline
\end{tabular}

After the base model was sufficiently studied, fractures were implemented into the reservoir description. The number of fractures, fracture half-length, and fracture width were changed so that the impact of that parameter on the production could be evaluated. The values used are typical values for CBM reservoirs. The fracture widths that were used were 0.01 " and 0.1 ", both reasonable values for hydraulic fractures in these types of plays. However, the frac engineer has less control over the fracture width than over other aspects of the stimulation design. 


\section{RESULTS AND DISCUSSION}

\subsection{Base Model Replication}

Dimensionless production type curves can be quickly and effectively created after sufficient simulation or known production data has been acquired. The assistance of computer simulation programs, such as Eclipse, can provide such data in a rapid and reliable fashion. Fortunately, the accuracy of such results can be tested, and were proved to be precise by the matching of previously known reservoir data. The results, which were expected, confirm the program's successful use and allow for further study. The results are viable and the effects of parameters such as well length and drainage area on reservoirs with rectangular drainage areas can be seen in the following figures.

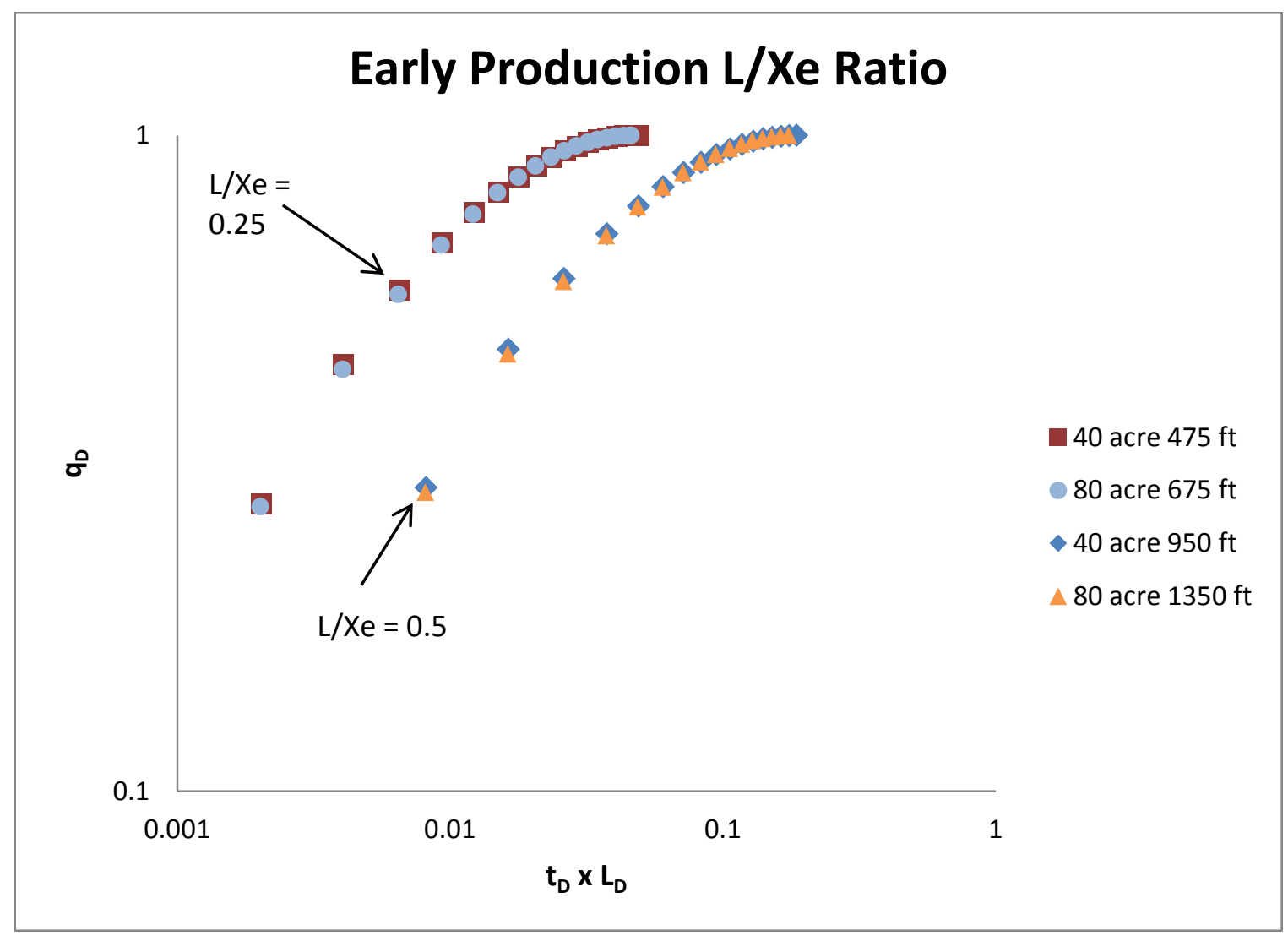

Figure 16. Early Production Impacted by L/Xe Ratio 


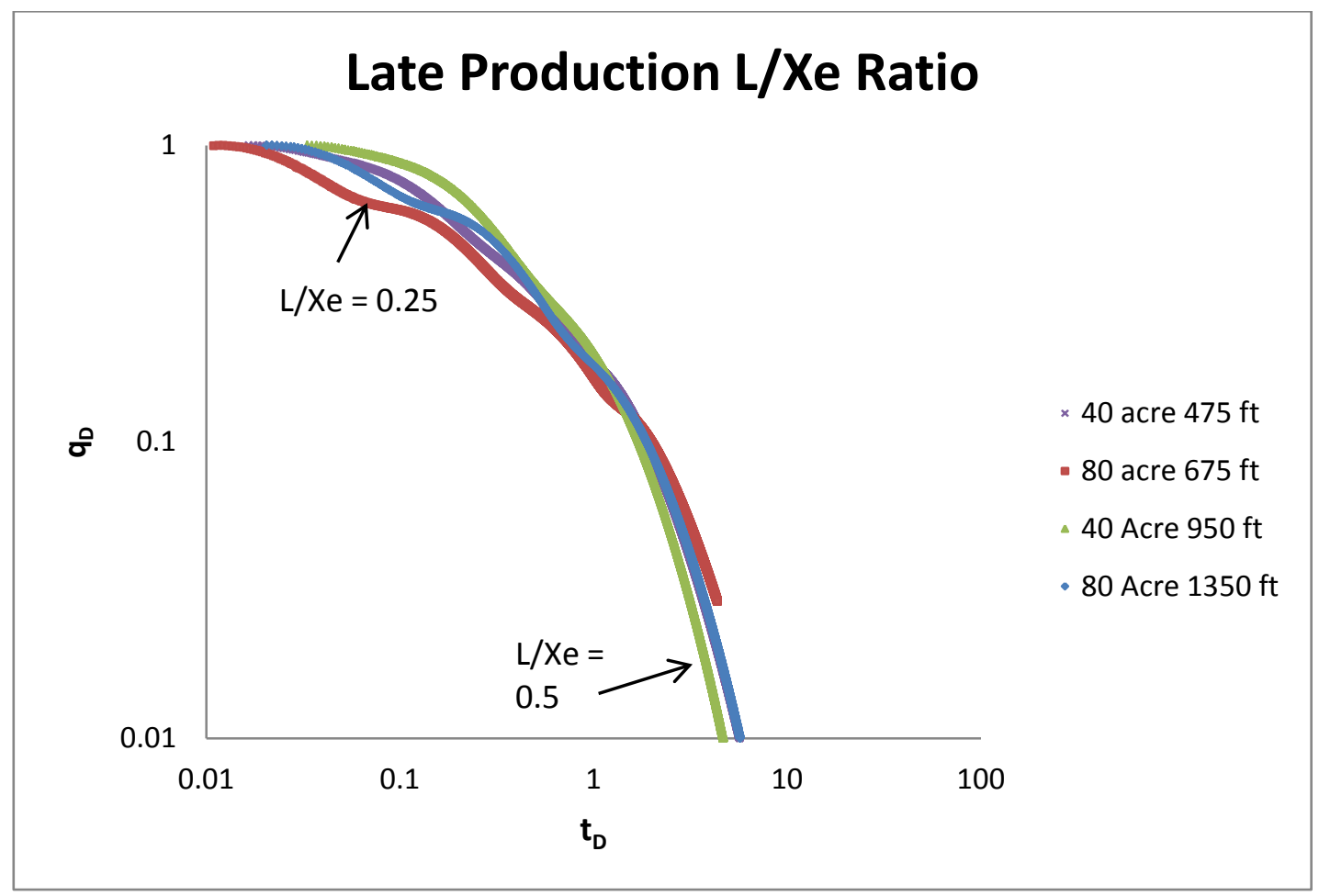

Figure 17. Late Production Impacted by L/Xe Ratio

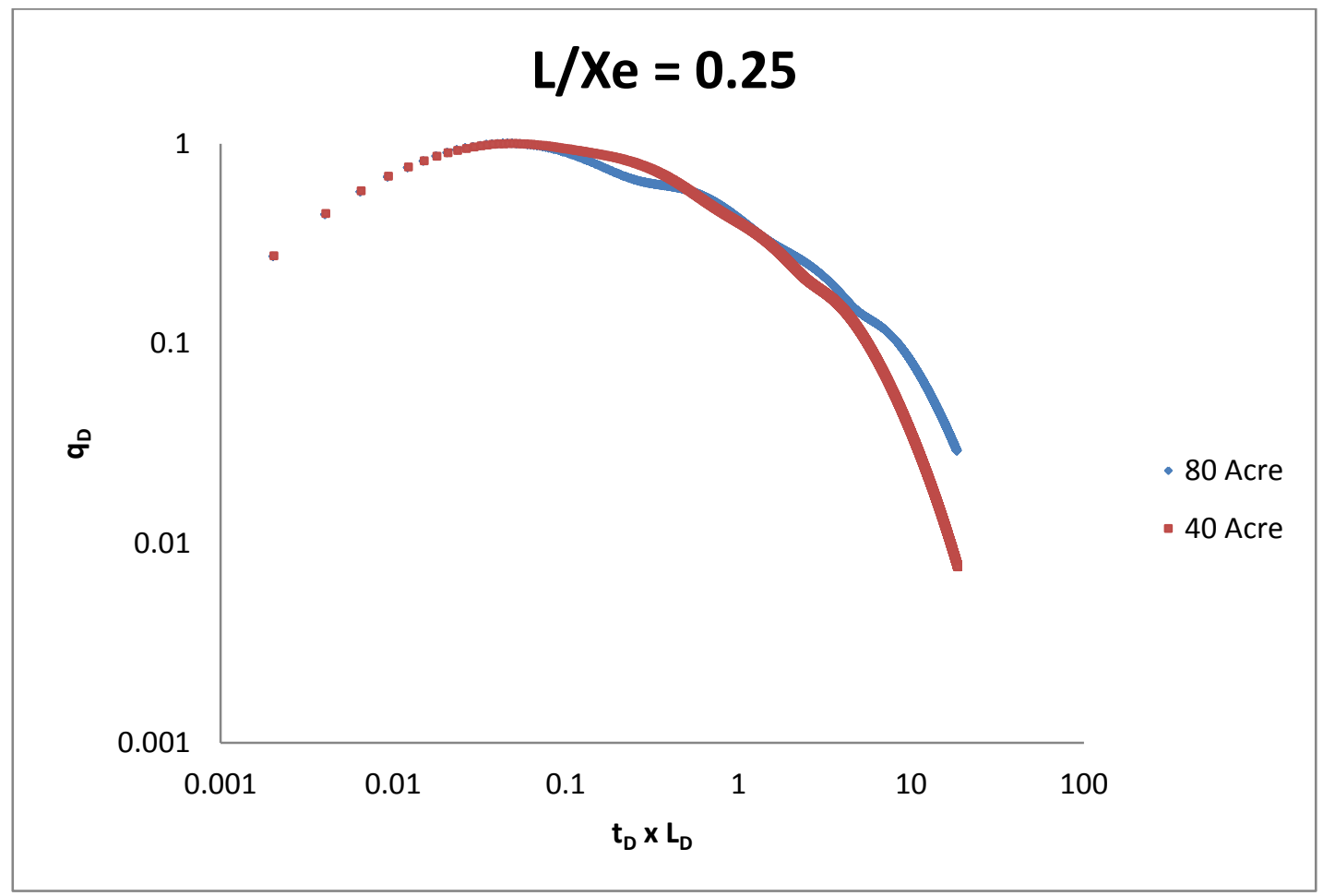

Figure 18. Production History for Length Ratio $=\mathbf{0 . 2 5}$ 


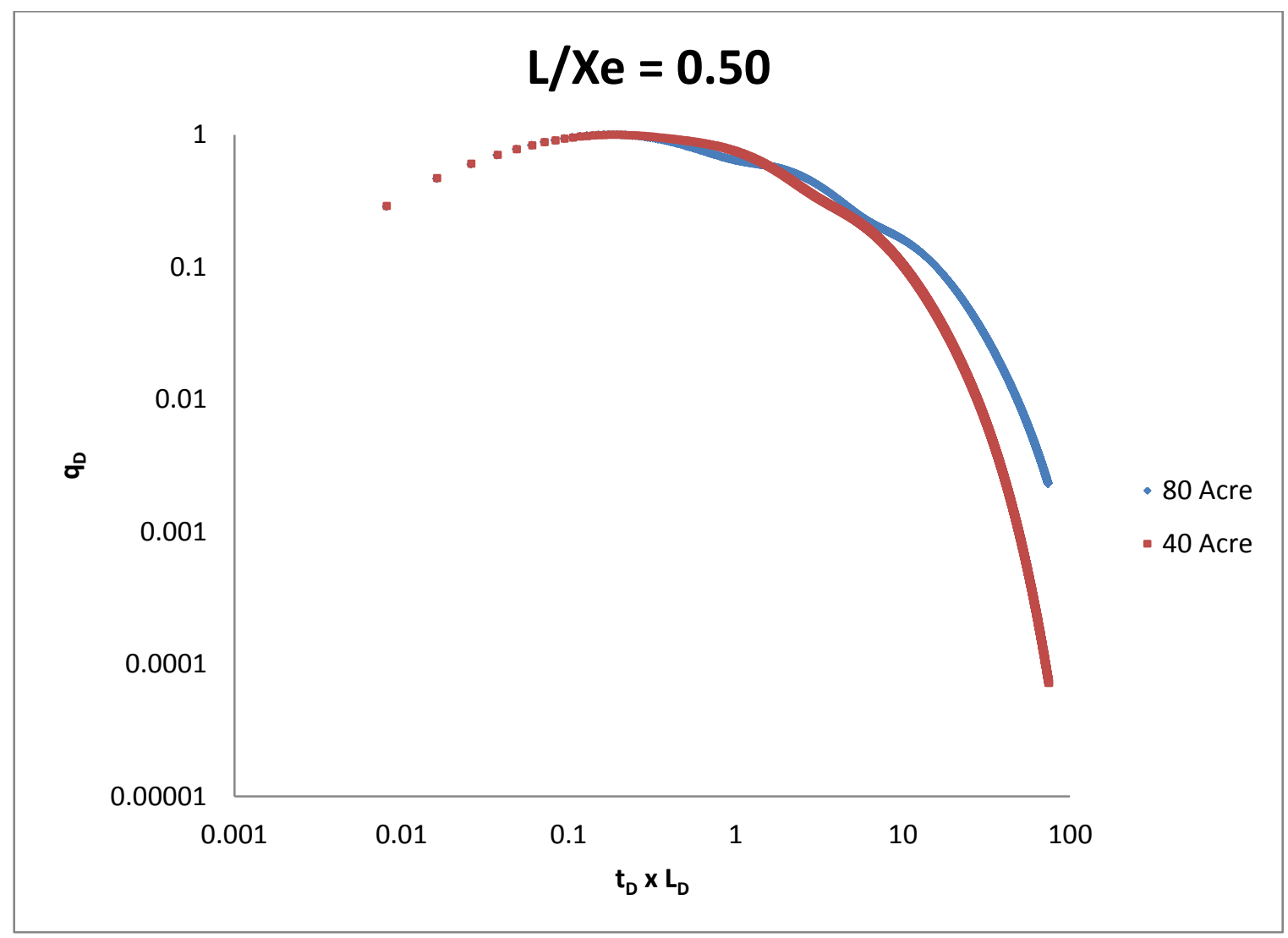

Figure 19. Production History for Length Ratio $=0.50$

After the confirmation of successful reservoir simulation with a known case, hydraulic fracturing can be initiated and various reservoir configurations can be studied.

\subsection{Case Study Results and Impacts of Fractures}

Hydraulic fractures can have a substantial impact on many different reservoirs. It is not uncommon for coalbed methane reservoirs to exhibit lower permeabilities than those used in the base model $(x=3.3 \mathrm{mD}, y=10 \mathrm{mD})$. Therefore, the permeability ratio will 
remain the same, but the actual bulk permeabilities will be lowed an order of magnitude $(x=0.33 \mathrm{mD}, y=1.0 \mathrm{mD})$. Also, because the hydraulic fractures will need to be placed normal to the reservoir's low permeability direction, the permeabilities will swap (that is, $x=1.0 \mathrm{mD}, y=0.33 \mathrm{mD}$ ). It is easier to change the permeability matrix of the model than reorient the lateral wellbore since the well needs to be along the length (and not the width) of the reservoir. When the permeabilities stay in the same direction, the effects of a fracture are negligible, as can be seen in Figure 20. Figure 21 illustrates the importance of maintaining a higher permeability normal to the fracture. Figure 22 shows the differences caused by the changed permeability direction. These effects are noticeable; however, the effects of the fracture compared to non-fractured data are negligible, likely due to the lower permeability conductivity as a result of the small fracture width $\left(w_{\mathrm{f}}=0.01^{\prime \prime}\right)$.

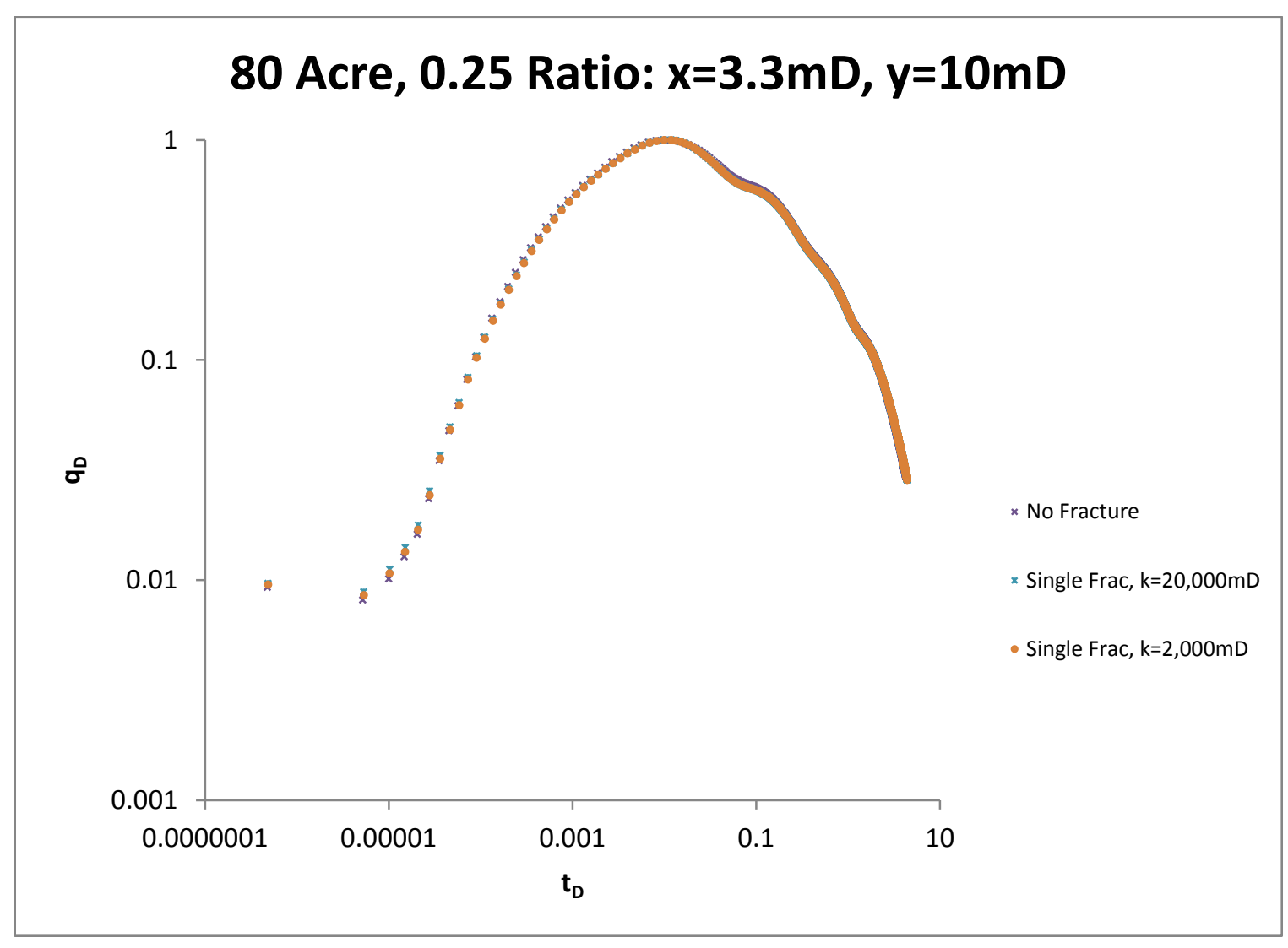

Figure 20. Effects of Fracture Parallel to High Permeability Direction 


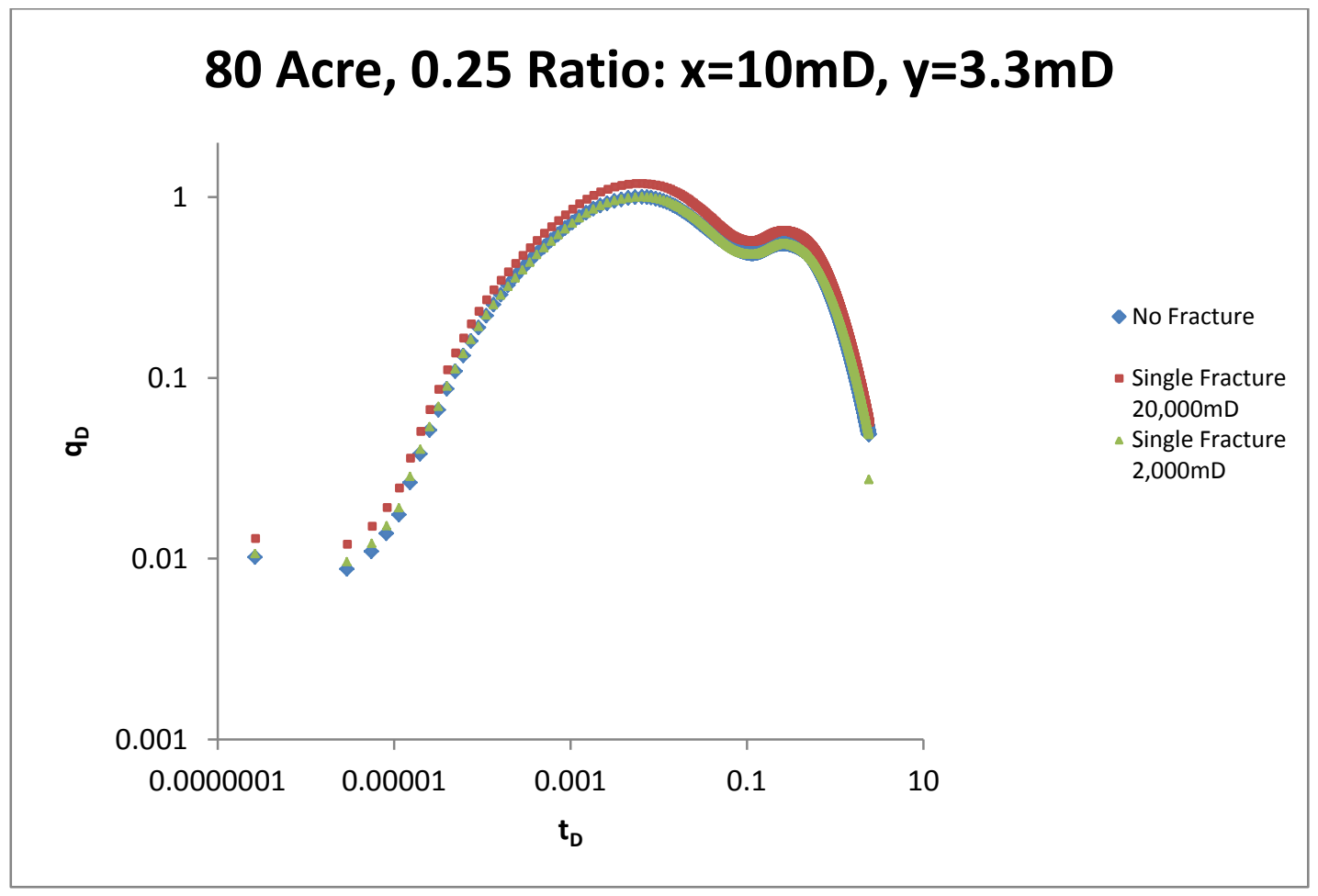

Figure 21. Effects of Fracture Normal to High Permeability Direction

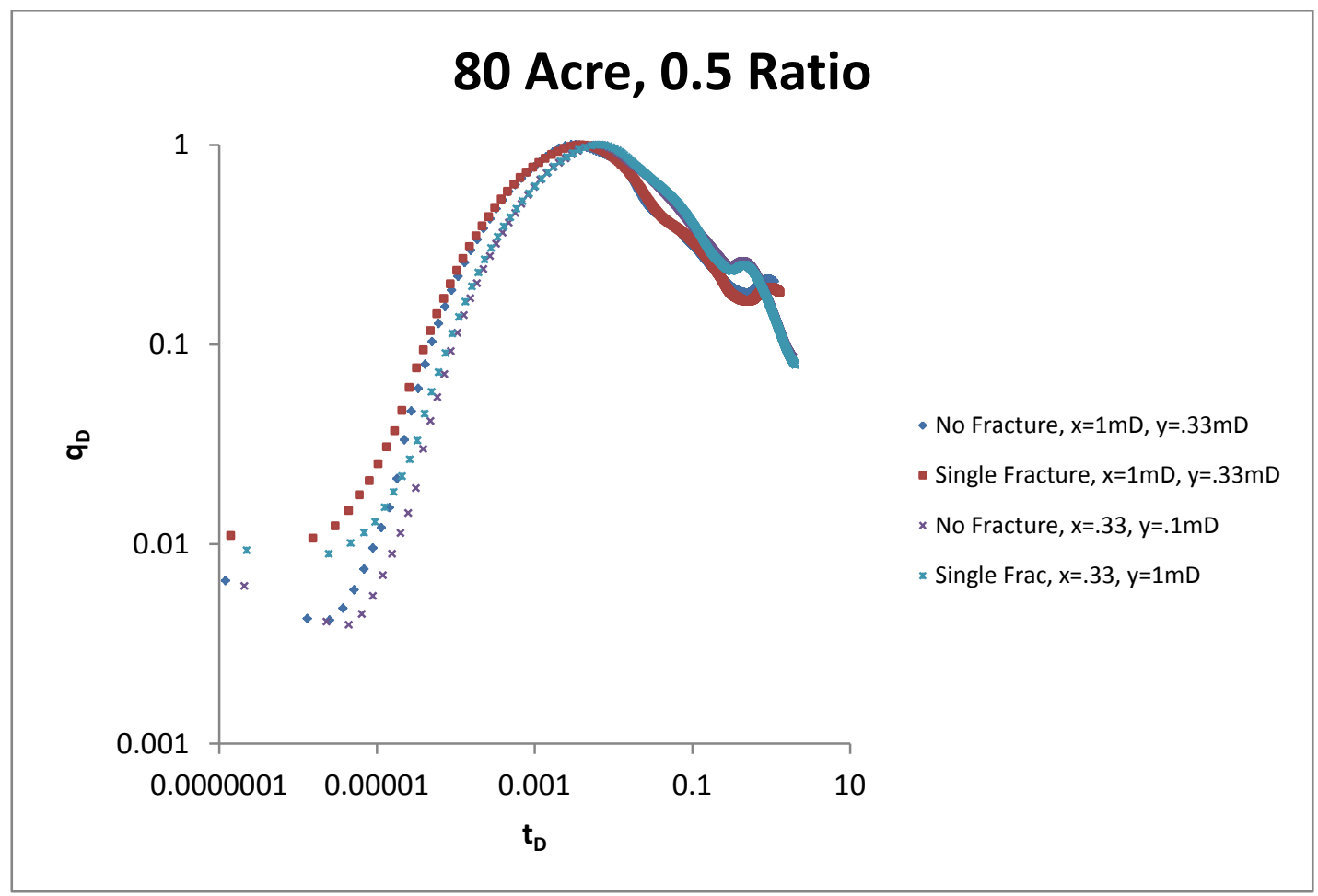

Figure 22. Effects of Permeability Matrix 
The effects of gas desorption time also have a critical impact on the reservoir's production. When the desorption time is less, the gas is able to escape the coal micropores and enter into the natural and hydraulic fracture matrix sooner. Thus, production is able to peak sooner and rates are also seen to be higher. Figure 23 shows these effects on a reservoir without fractures while Figure 24 shows the effects on a reservoir fractured four times with $k_{f}=20,000 \mathrm{mD}$ and $\mathrm{w}_{\mathrm{f}}=0.01^{\prime \prime}$.

Coal gas concentration (CGC) also has a small effect on the reservoir performance. As the CGC increases, so does the total production and the peak production. The peak production rate also occurs at a slightly sooner time. This higher total production is due to the higher amount of methane found in the coal (initial Gasin-Place). See Figure 25 for the effects of coal gas concentration.

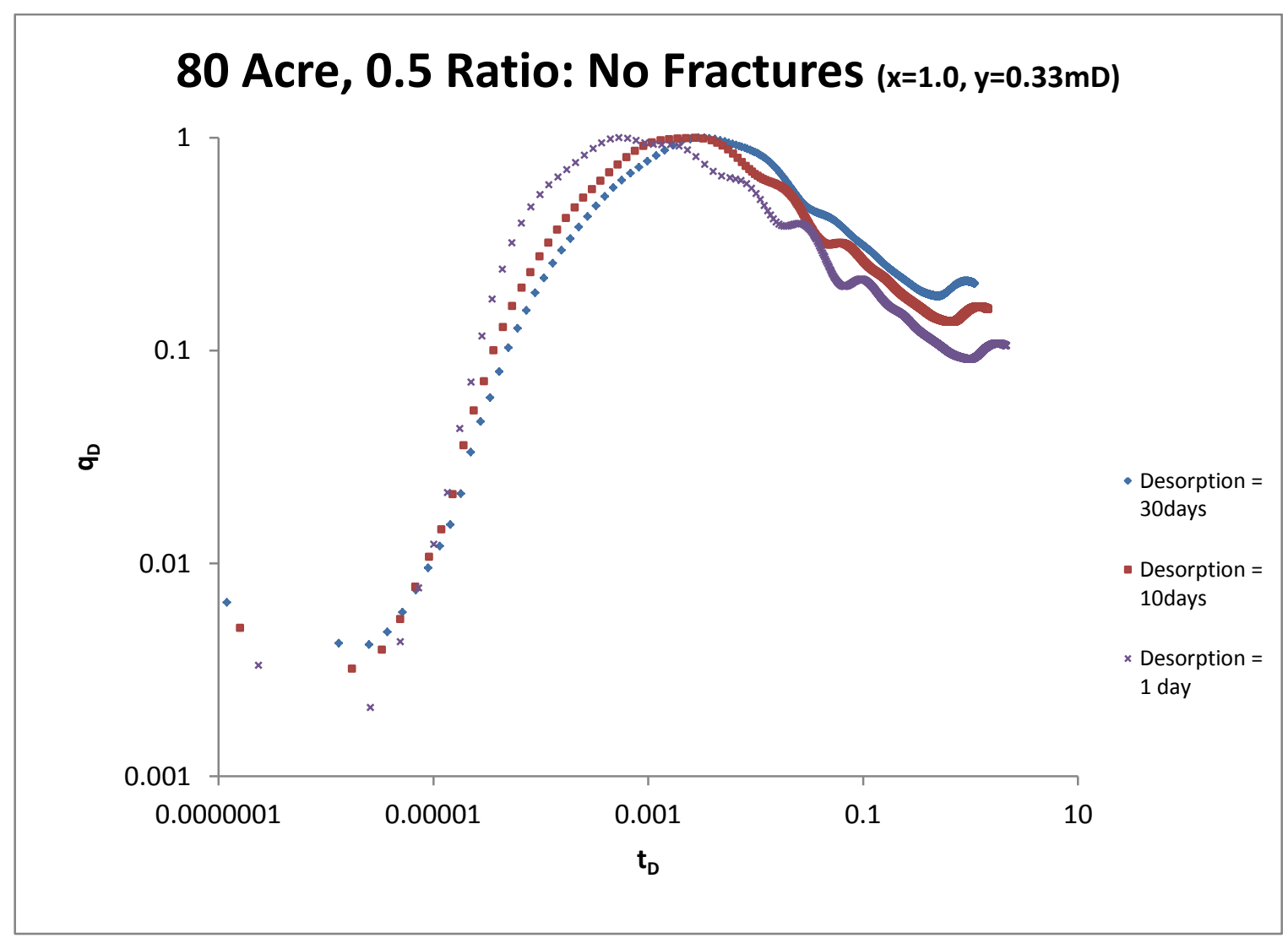

Figure 23. Effects of Desorption Time 


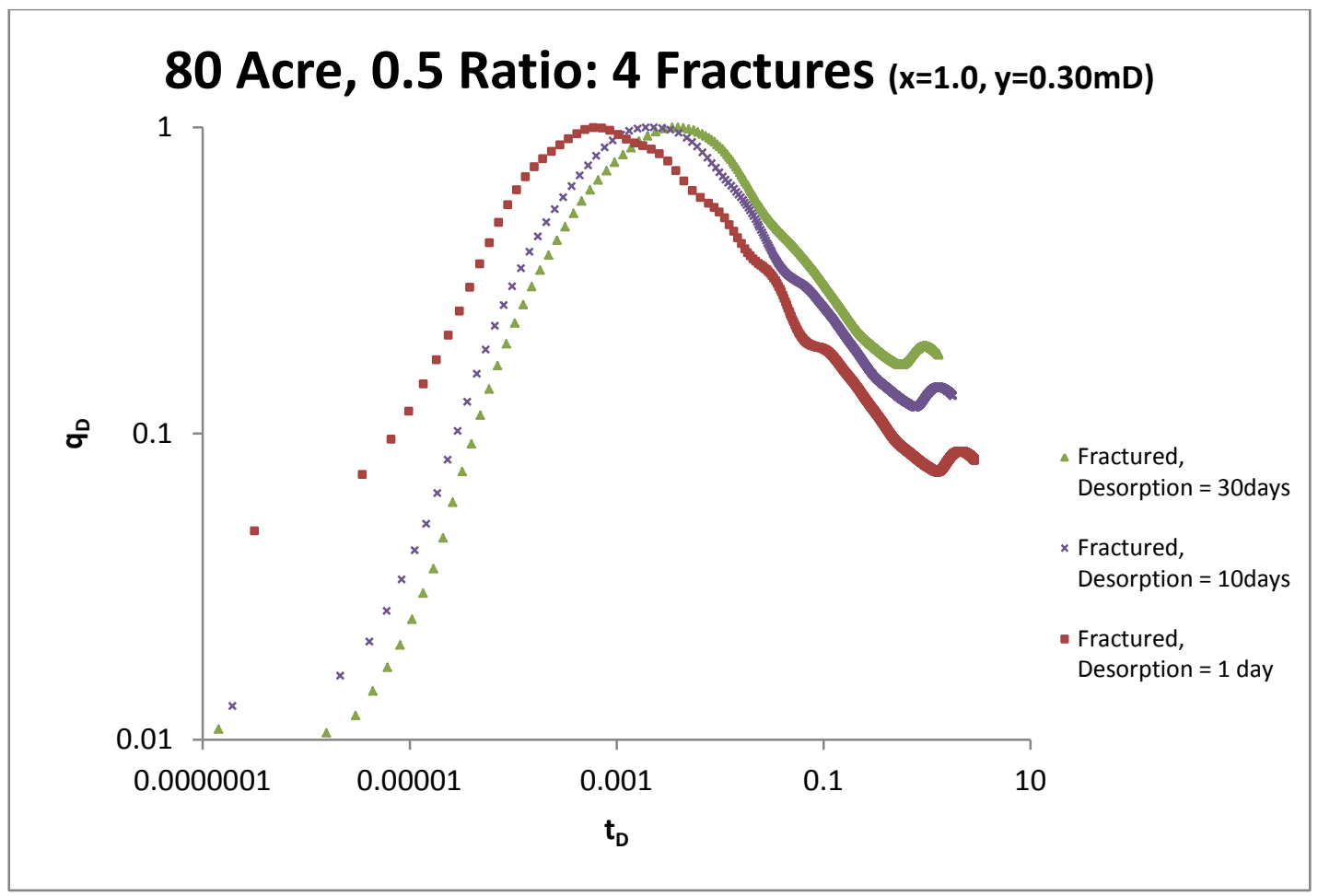

Figure 24. Effects of Desorption Time on Fractured Reservoir

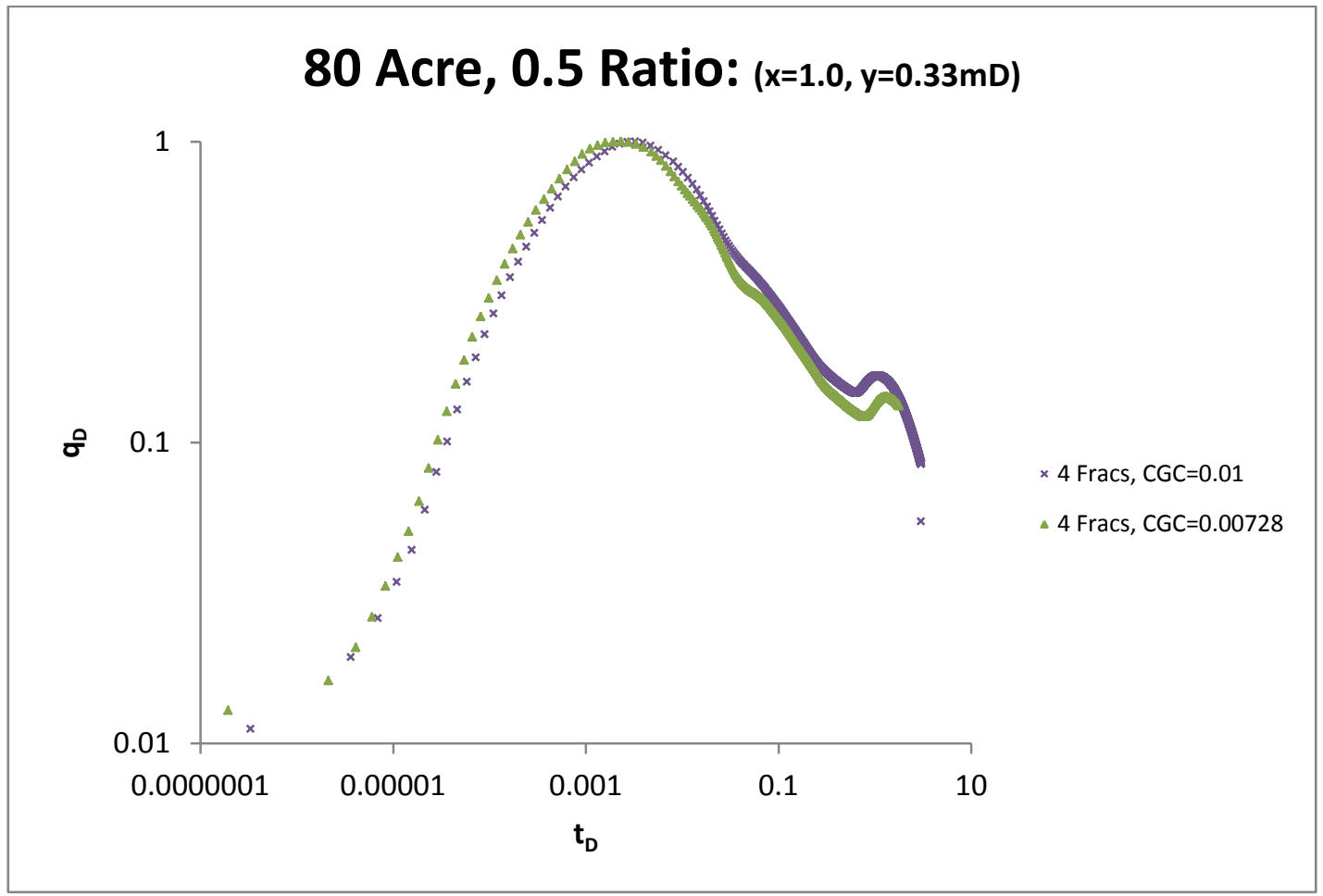

Figure 25. Effects of Coal Gas Concentration on Fractured Reservoir 
Fracturing the reservoir has a substantial impact, especially considering other reservoir characteristics that can also affect a reservoir's performance. The increased reservoir permeability instigated by hydraulic fracturing can cause higher peak production and increased total production in CBM and unconventional reservoirs. Therefore, an increased number of fractures should also increase these production characteristics. The total number of fractures implemented into a reservoir is a function of many different aspects, including reservoir size and economics. An experienced engineer will need to consider many different things before deciding how many fractures to use in a reservoir, but the effects are clear, as can be seen in Figure 26 and Figure 27.

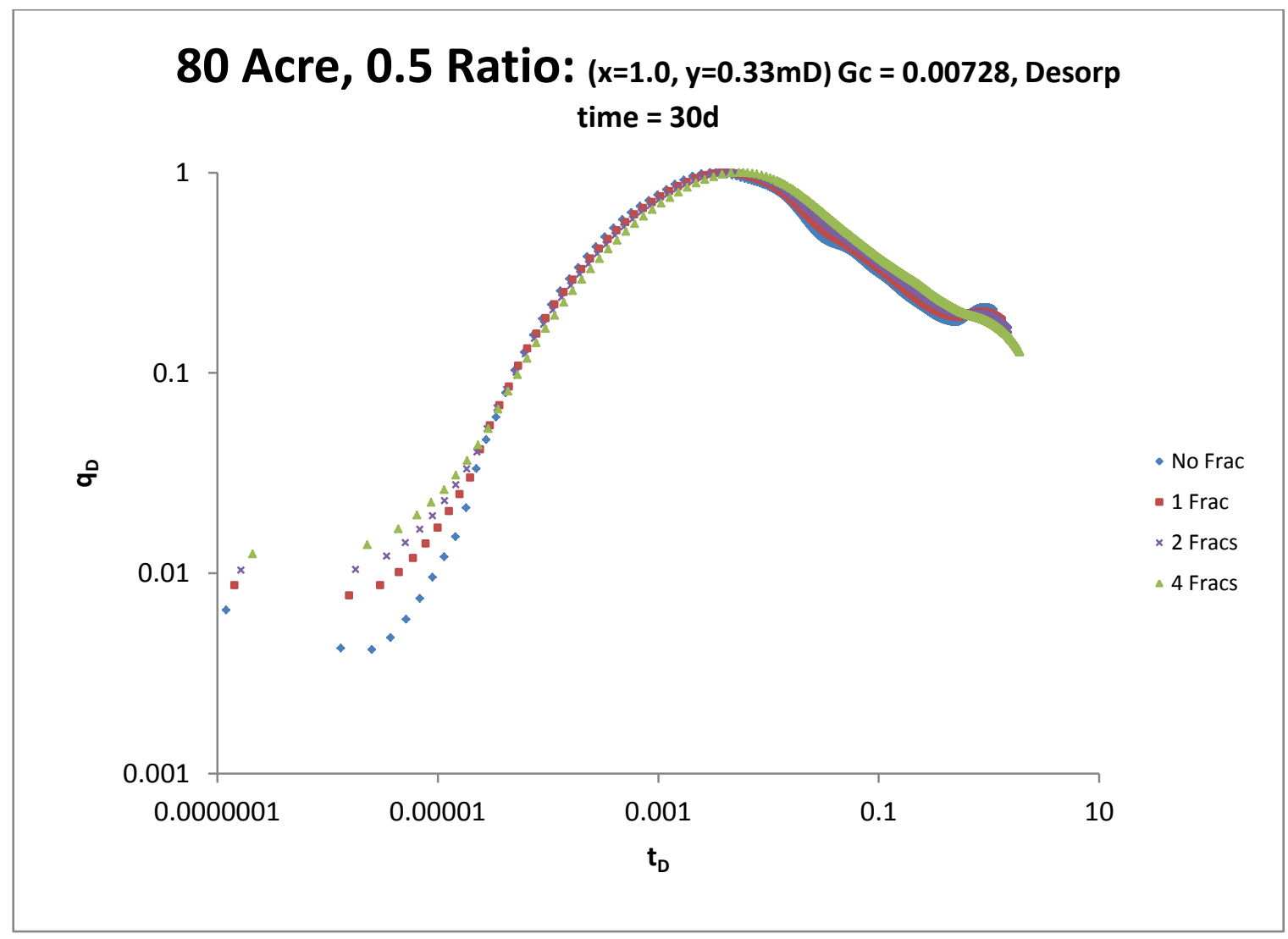

Figure 26. Effects of Increased Number of Fractures, L/Xe=0.50 


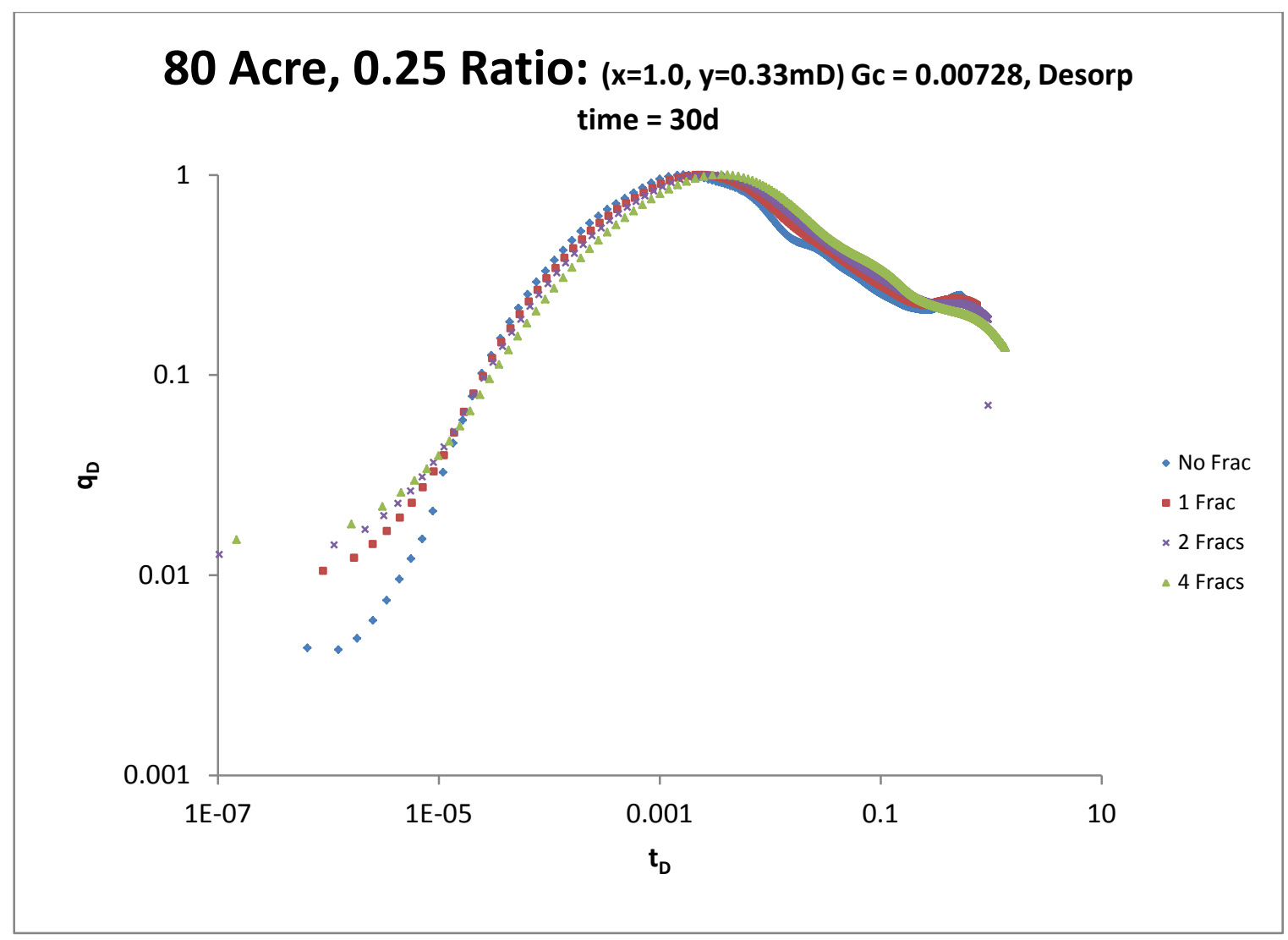

Figure 27. Effects of Increased Number of Fractures, L/Xe=0.25

In addition, the fracture half-length is a fundamental factor of the fracture design. Therefore, it is expected that the half-length will too have an effect on the reservoir's production and performance. It was seen, however, that the effects of fracture half-length do not affect the production as fundamentally as the fracture width did. However, the effects of half-length are shown in Figure 28 and the impact that fracture width has is visible in Figure 29. 


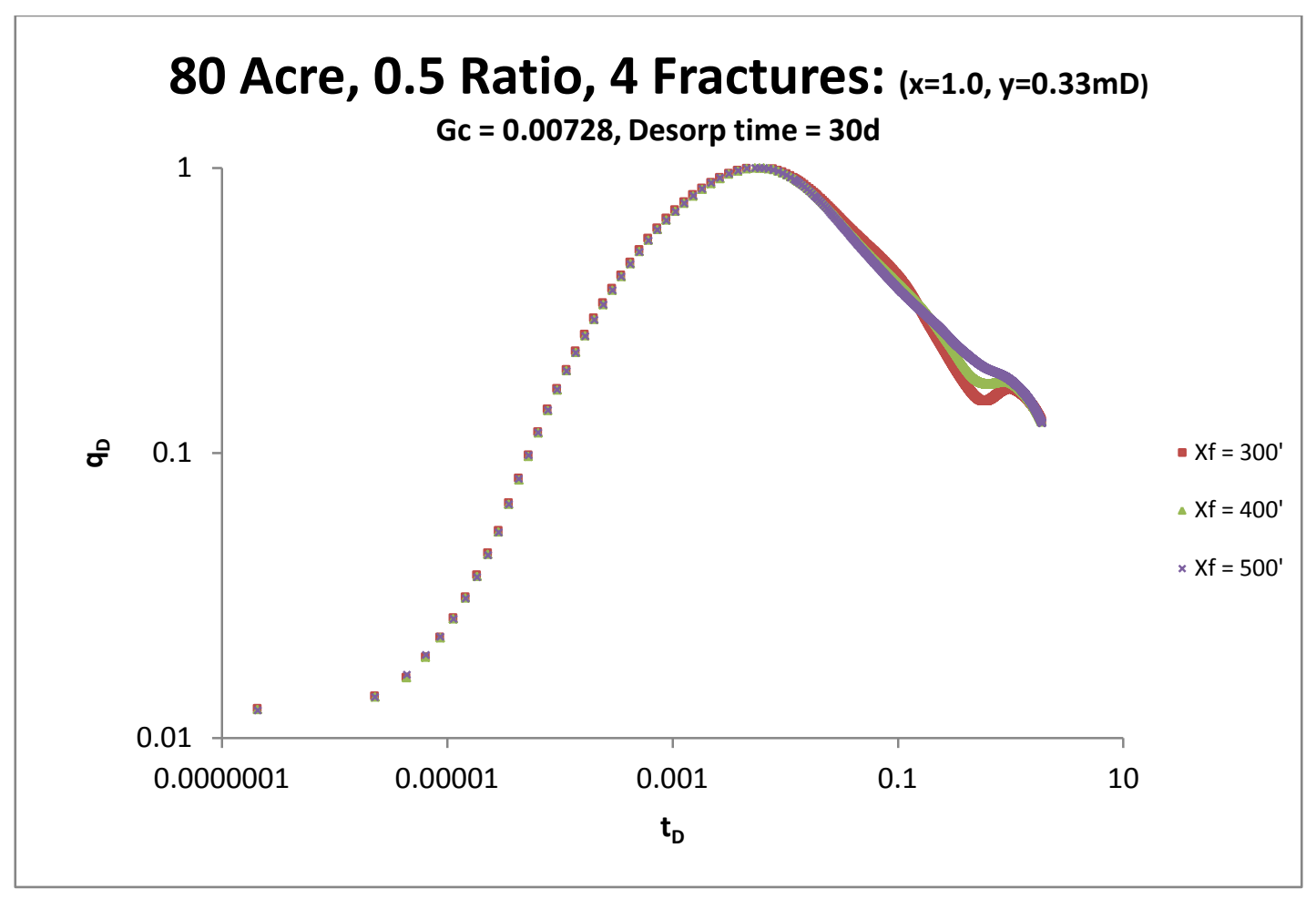

Figure 28. Effects of Fracture Half-Length

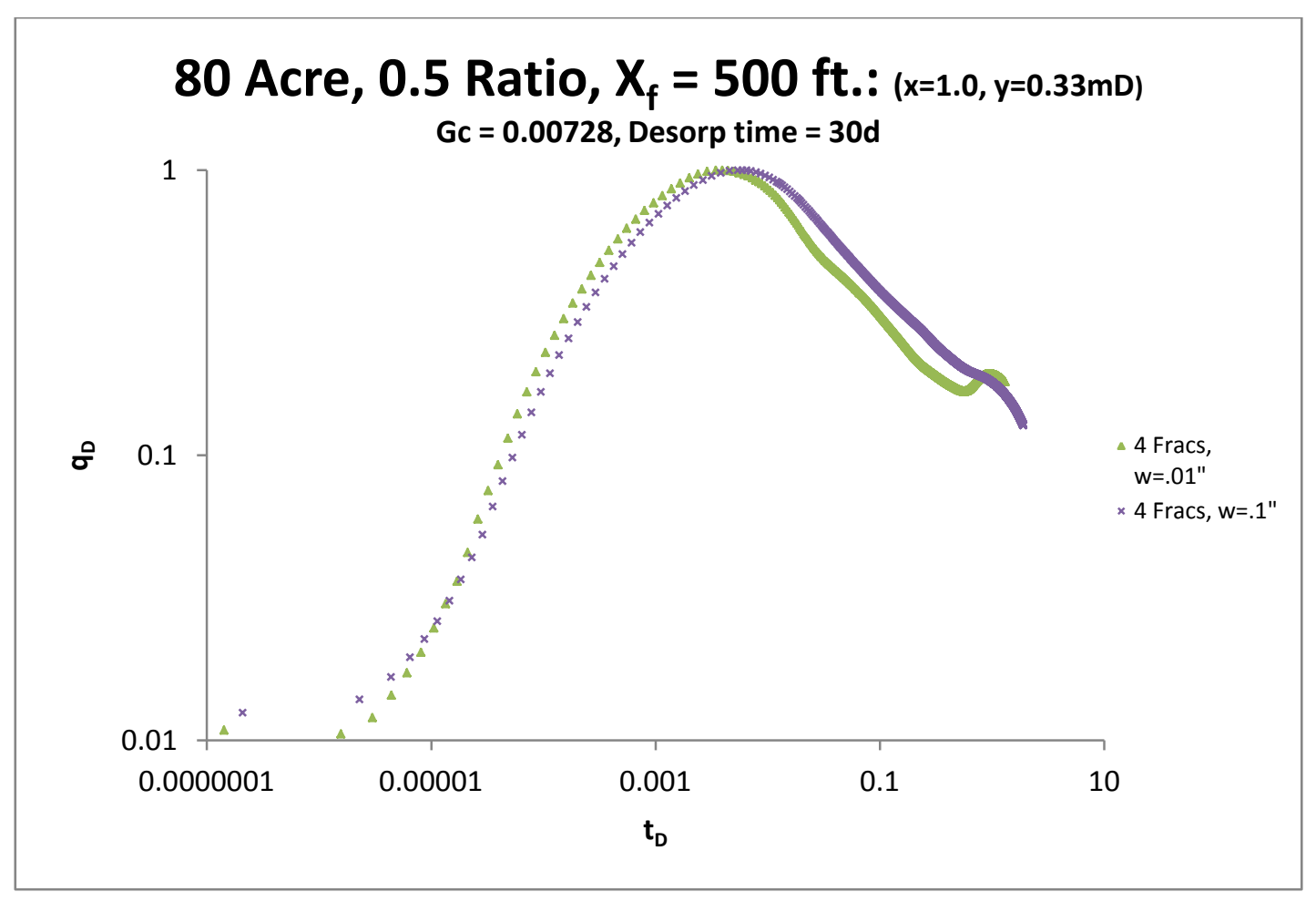

Figure 29. Effects of Fracture Width 


\subsection{Regression Analysis}

Due to the nature of the hydraulic fracturing process, many different aspects are under attempt to be controlled by the fracturing engineer. The production performance is greatly influenced by these characteristics, as well as many others. Since the most studied fracture characteristics studied in this research include fracture width and permeability (fracture conductivity), fracture half length, and the ratio of the lateral well length to reservoir length, a regression analysis was conducted in order to attempt to predict the peak flow rate.

Peak flow rate will vary depending on several other reservoir parameters, such as the desorption time and the coal gas concentration. However, keeping these factors constant, a regression equation was developed. If coal gas concentration is kept at $0.00728 \mathrm{Mscf} / \mathrm{ft} 3$ and the desorption time is at 30 days, the following equation has been developed to relate fracture characteristics. Four fractures were also implemented for the data used to develop the regression, and therefore the fracture concentration is varied (as L/Xe varies).

$$
q_{\text {peak }}=78.5 \frac{L}{X_{e}}+0.0052 X_{f}+0.0117 k_{f} w_{f}+1.49
$$

Since this equation for $\mathrm{q}_{\text {peak }}$ is only maintained when the desorption time and coal gas concentration are known constants, an equation relating the peak flow rate at other values of those variables would be useful. Therefore, another equation has been developed to account for these variables as well. Furthermore, an equation providing a dimensionless peak flow rate would allow the engineer to utilize that known value on a type curve. Hence, dimensionless peak flow rate was first calculated from the known peak flow rates and followed by a regression in order to determine a correlation for that. The equation used to determine dimensionless peak flow rate is as follows. 


$$
q_{\text {peak }}{ }_{D}=\frac{q_{\text {peak }} 1422 T \mu z}{k h\left(p_{c}^{2}-p_{w f}^{2}\right)} \ln \frac{r_{e}}{r_{w}}-.75+s
$$

This equation provided the needed dimensionless values for determining the correlation between dimensionless peak flow rate and the reservoir and fracture characteristics.

$$
\begin{gathered}
q_{\text {peak }}{ }_{D}=411.5 G_{c}-0.327 t_{\text {Desorp }}+2.25 \times 10^{-4} w_{f} k_{f}-6.46 \times 10^{-4} X_{f}+ \\
0.1337 N_{\text {fracs }}+2.12 L{ }^{L} X e^{-2.584 \ldots \ldots \ldots \ldots \ldots \ldots . . ~(4.3) ~}
\end{gathered}
$$




\section{CONCLUSIONS AND RECOMMENDATIONS}

The research presented in this report has intended to provide development of type curves for CBM reservoirs with lateral wellbores and hydraulic fracturing implemented. As well, a set of equations for developing an estimate to predict peak flow rate and dimensionless peak flow rate have also been investigated, based on certain common characteristics. The research took into account reservoir parameters and hydraulic fracturing properties to determine the impacts on production. After continuing to evaluate the results, the following conclusions and recommendations were made:

1. Reservoir production history, including reservoirs hydraulically fractured, can be slightly impacted by reservoir characteristics such as L/Xe, coal gas concentration, and desorption time.

2. Coalbed methane reservoir production history can be significantly impacted by hydraulic fracturing. This affects the peak flow rate, but not the shape of the type curve.

3. The impact that the hydraulic fracturing has is a result of the fracture characteristics. Namely, these characteristics include fracture conductivity and fracture half-length, with the conductivity having the most significant impact.

4. Type curves with hydraulic fractures exhibit the same general shape as those without fractures. Only the peak flow rate and early-time dewatering phase yields unique distinction.

5. A reliable correlation for predicting dimensionless peak gas rate for CBM has been developed, allowing type curves to be used as a tool for predicting production.

CBM reservoirs are a significant part of the natural gas supply equation. The increased production that can be achieved through hydraulic fracturing will provide more economical resources. Because the fracturing process will be common to 
achieving higher economic value, its implementation is inevitable. Therefore, reliable type curves to predict production are crucial and of great importance. Further development will continue to aid in the production of unconventional gas reservoirs. 


\section{NOMENCLATURE}

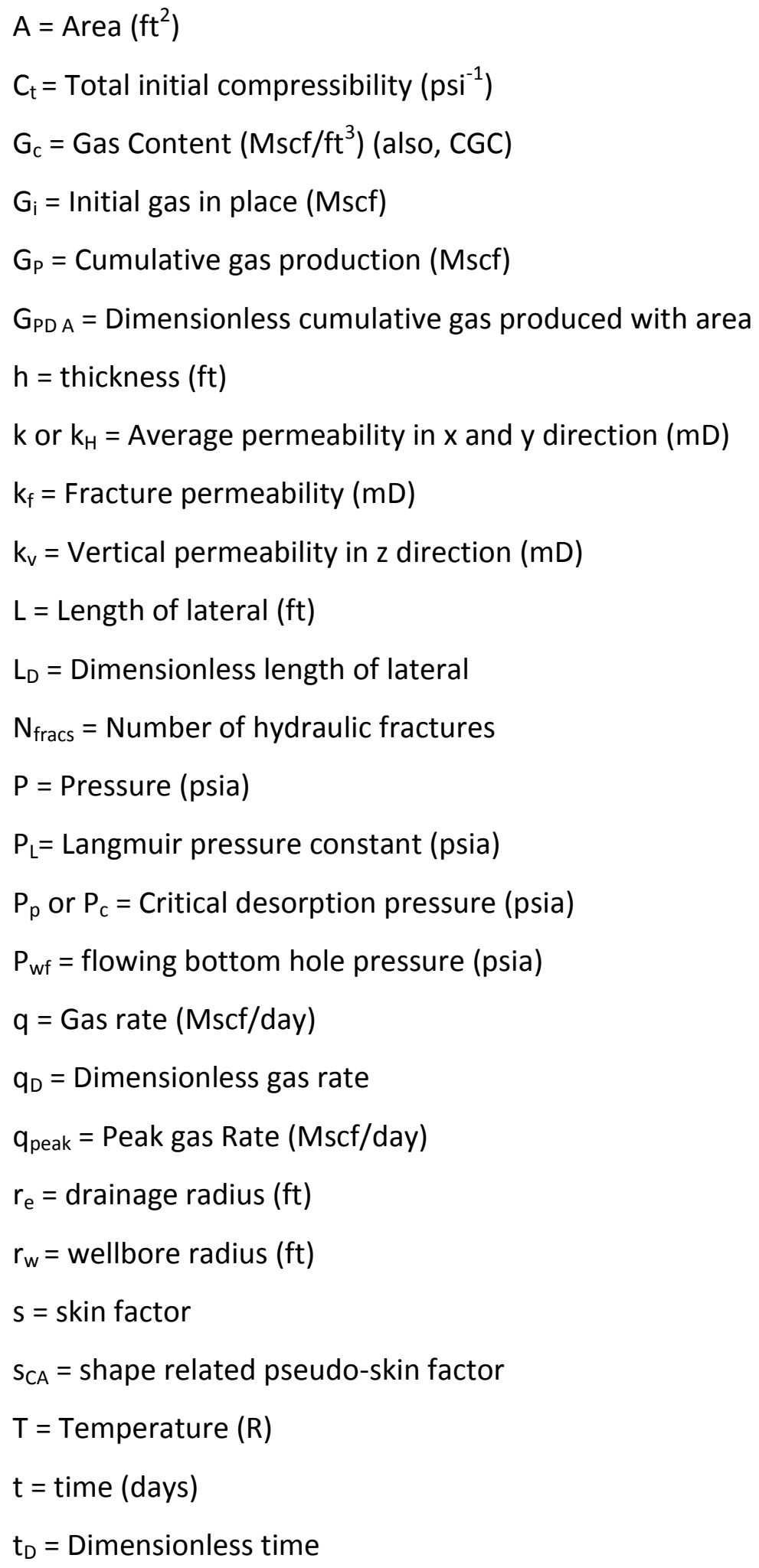




$$
\begin{aligned}
& t_{D A}=\text { Dimensionless time with area } \\
& t_{\text {desorp }}=\text { Desorption time (days) } \\
& V_{L}=\text { Langmuir volume constant (Scf/ton) } \\
& W_{f}=\text { Fracture width (in.) } \\
& X_{f}=\text { Fracture half-length (ft) } \\
& X_{e}=\text { Length of reservoir }(\mathrm{ft}) \\
& Y_{e}=\text { Width of reservoir }(\mathrm{ft}) \\
& Z=z \text {-factor } \\
& \mu=\text { Viscosity (cp) } \\
& \phi=\text { Porosity (fraction) }
\end{aligned}
$$




\section{REFERENCES}

1. Unconventional Gas." Advanced Resources International, Inc.. N.p., n.d. Web. 11 May 2011. <http://www.adv-res.com/unconventional-gas-nonconventionalresources.asp>.

2. "Directional Drilling Technology." U.S. Environmental Protection Agency. 27 May $2011<$ http://www.epa.gov/coalbed/docs/dir-drilling.pdf>.

3. "Horizontal Wells." Center for Public Environmental Oversight (2010): n. pp. Web. 28 May 2011. <http://www.cpeo.org/techtree/ttdescript/horzwel.htm>.

4. "Wellbore Storage." International Petroleum Industry Multimedia System (2009): n. pg. Web. 18 May 2011. http://ipims.com/data/fe22/E2809.asp?UserID=\&Code=3127

5. Diamond, W. P. and Oyler, D. C., 1986, "Direction Drilling for Degasfication of Coalbeds in Advance of Mining", in Methane Control Research: Summary of Results, 1964 - 1980, U.S. Bureau of Mines Bulletin 687, pp. 128-133

6. "Directional Drilling Technology." U.S. Environmental Protection Agency. 27 May 2009 <http://www.epa.gov/coalbed/docs/dir-drilling.pdf>.

7. Aminian, Kashy. Lectures 6 and 10. Advanced Natural Gas Engineering. Morgantown: West Virginia University, Spring 2009.

8. Rogers, Ruby E., Muthukumarappan Ramurthy, Gary Rodvelt, and Mike Mullen.Coalbed Methane: Principles and Practices. 3rd Edition. 2007, 20-21.

9. Olszewski, A.J. and Schraufnagel, R.A.: "Development of Formation Evaluation Technology for Coalbed Methane Development," Quarterly Review of Methane from Coalseams Technology (October 1992) 10, No. 1, 27-35.

10. Joshi, S.D.. Horizontal Well Technology. Ok: PennWell, 1991. Print.

11. Aminian, K., and S. Ameri. "Predicting Horizontal Well Production Performance Using Type Curves." SPE 19342(1989).

12. John Squarek and Mike Dawson, Coalbed methane expands in Canada, Oil \& Gas Journal, 24 July 2006, p.37-40. 
13. Howard, G.C. and C.R. Fast (editors), Hydraulic Fracturing, Monograph Vol. 2 of the Henry L. Doherty Series, Society of Petroleum Engineers New York, 1970

14. Bell, G.J., Jones, A.H., Morales, R.H., and Schraufnagel, R.A.: "Coalseam Hydraulic Fracture Propagation on a Laboratory Scale," Proc., CBM Symposium, Tuscaloosa, Alabama (April 1989) 417-425.

15. "Fracturing Technologies for Improving CMM/CBM Production." Coalbed Methane Outreach Program (CMOP). Washington, DC: Advanced Resources Internationa, 2008. Print

16. Rightmire, C.T.: "CBM Resource," CBM Resources of the United States, American Association of Petroleum Geologists Studies in Geology (1984) No. 17, 8-9.

17. McElhiney, J.E., Koenig, R.A., and Schraufnagel, R.A.: "Evaluation of CBM Reserves Involves Different Techniques," Oil \& Gas J. (October 1989) 87, No. 44, 63-72.

18. Cramer, David D. "Stimulating Unconventional Reservoirs: Lessons Learned, Successful Practices, Areas for Improvement." SPE Unconventional Reservoirs Conference. (2008): Print.

19. Space Binder, Kurt. The Monte Carlo Method in Condensed Matter Physics. 1995. New York: Springer.

20. Fetkovich, M.J. "Decline Curve Analysis Using Type Curves." SPE 4629. (1980): Print.

21. Holditch, Stephen A., Kent Perry, and John Lee. "Unconventional Gas ReservoirsTight Gas, Coal Seams, and Shales." National Petroleum Concil. (2007): Print.

22. Eclipse Reservoir Engineering Software Manual. 2007. Schlumberger.

23. Drinkard, Dylan. "Predicting the Performance of Horizontal Wells in Unconventional Gas Reservoirs." Morgantown, WV: West Virginia University, 2009. Print. 
24. "Cleat and Joints." Coal Mine Outbursts. pag. Web. 13 Jun 2011. <http://outburst.uow.edu.au/html/cleat_joints_pg1.html>.

25. Aminian K., S. Ameri, M. Sanchez, A. Garcia, and A. Bhavsar. "Type Curves for Coalbed Methane Production Prediction." SPE. 91482(2004).

26. "CBM Concepts." F.A.S.T. CBM. Fekete Associates Inc., 2011. Web. 29 May 2011. <http://www.fekete.com/software/cbm/media/webhelp/c-te-concepts.htm>.

27. Lisa, Sumi. Oil and Gas at Your Door. 2nd. Durango, Colorado: Oil and Gas Accountability Project, 2005. 72. Print. 